\title{
Tonicity inversely modulates lipocalin-2 (Lcn2/24p3/NGAL) receptor (SLC22A17) and Lcn2 expression via Wnt/ $\beta$-catenin signaling in renal inner medullary collecting duct cells: implications for cell fate and bacterial infection
}

\author{
R. Betten ${ }^{1+}$, B. Scharner ${ }^{1+}$, S. Probst ${ }^{1}$, B. Edemir ${ }^{2}$, N. A. Wolff ${ }^{1}$, C. Langelueddecke ${ }^{1}$, W.-K. Lee ${ }^{1}$ and F. Thévenod ${ }^{1 *}$ (D)
}

\begin{abstract}
Background: We have previously evidenced apical expression of the 24p3/NGAL/lipocalin-2 receptor (Lcn2-R; SLC22A17) in inner medullary collecting duct (IMCD) cells, which are present in vivo in a hyperosmotic/-tonic environment that activates canonical Wnt/ $\beta$-catenin signaling. The localization of Lcn2-R in the inner medulla is intriguing considering local bacterial infections trigger toll-like receptor-4 (TLR-4)-mediated secretion of the bacteriostatic Fe ${ }^{3+}$-free (apo-)Lcn2.

Aim: To determine the effects of osmolarity/tonicity changes, Wnt/ $\beta$-catenin and TLR-4 activation on Lcn2-R and Lcn2 expression and cell viability in rat primary IMCD and mouse (m)IMCD3 cells.

Methods: Normosmolarity/-tonicity was $300 \mathrm{mosmol} / \mathrm{l}$ whereas hyperosmolarity/-tonicity was induced by adding $100 \mathrm{mmol} / \mathrm{l} \mathrm{NaCl}+100 \mathrm{mmol} / \mathrm{I}$ urea (600 mosmol/l, 1-7 days). Lcn2-R and Lcn2 expression were determined by qPCR, immunoblotting, flow cytometry and immunofluorescence microscopy. $\beta$-catenin was silenced by RNAi. Cell viability/death was determined with MTT and LDH release assays. TLR-4 was activated by bacterial lipopolysaccharides (LPS).
\end{abstract}

Results: Hyperosmotic/-tonic media upregulated Lcn2-R by 4-fold and decreased Lcn2 expression/secretion, along with Wnt/ $\beta$-catenin activation, in IMCD cells. These effects of hyperosmotic/-tonic media on Lcn2-R/Lcn2 expression were reverted by normosmolarity/-tonicity, $\beta$-catenin silencing and/or LPS. Exposure of cells with endogenous or stably overexpressing Lcn2-R to apo-Lcn2 or LPS decreased cell viability.

(Continued on next page)

\footnotetext{
* Correspondence: frank.thevenod@uni-wh.de

${ }^{\dagger}$ R. Betten and B. Scharner contributed equally to this work.

'Department of Physiology, Pathophysiology \& Toxicology and ZBAF (Centre

for Biomedical Education and Research), Faculty of Health, School of

Medicine, Witten/Herdecke University, Stockumer Str 12 (Thyssenhaus),

D-58453 Witten, Germany

Full list of author information is available at the end of the article
}

(c) The Author(s). 2018 Open Access This article is distributed under the terms of the Creative Commons Attribution 4.0 International License (http://creativecommons.org/licenses/by/4.0/), which permits unrestricted use, distribution, and reproduction in any medium, provided you give appropriate credit to the original author(s) and the source, provide a link to the Creative Commons license, and indicate if changes were made. The Creative Commons Public Domain Dedication waiver (http://creativecommons.org/publicdomain/zero/1.0/) applies to the data made available in this article, unless otherwise stated. 
(Continued from previous page)

Conclusions: Lcn2-R upregulation and Lcn2 downregulation via Wnt/ $\beta$-catenin may promote adaptive osmotolerant survival of IMCD cells in response to hyperosmolarity/-tonicity whereas Len2 upregulation and Lcn2-R downregulation via TLR-4 and/or normosmolarity/-tonicity may protect IMCD cells against bacterial infections and prevent autocrine death induction by Lcn2.

Keywords: Kidney, hypertonicity, osmotic stress, cell death, proliferation, lipocalin-2, lipocalin-2 receptor, Wnt/ beta-catenin, lipopolysaccharide

\section{Background}

The cells of the inner medullary collecting duct (IMCD) are key elements of the nephron in the process of urinary concentration and dilution [1]. For these processes to be operative, interstitial hyperosmolarity/-tonicity needs to be established by accumulation of high interstitial levels of $\mathrm{NaCl}$ and urea [2,3]. However, the hypertonic effect of high $\mathrm{NaCl}$ is stressful to cells, may alter cellular functions and even kill cells by apoptosis (reviewed in [4]). Cells can counteract high osmolality stress by initiating survival mechanisms that activate the transcription factor TonEBP/OREBP/NFAT5 (reviewed in [4]). These survival mechanisms include accumulation of organic osmolytes and increased expression of heat shock proteins through numerous pathways, resulting in osmotolerance. Hence, the unique hypertonic environment in the renal medulla induces a nephron segment-specific gene expression pattern [5].

Neutrophil gelatinase-associated lipocalin (NGAL in humans, siderocalin/24p3 in rodents) or lipocalin-2 (Lcn2) is secreted by cells [6] in an $\mathrm{Fe}^{3+}$-free apo form, which binds $\mathrm{Fe}^{3+}$ through association with bacterial siderophores (forming holo-Lcn2). Apo-Lcn2 hence plays an important role in antibacterial innate immunity [7]. Several studies have demonstrated that apo-Lcn2 induces apoptosis in Lcn2-R expressing cells $[8,9]$, whereas holo-Lcn2 is anti-apoptotic and may even promote cell proliferation, e.g. in cancer cells [10]. Lcn2 is expressed in cells as a non-glycosylated $\sim 22-\mathrm{kDa}$ precursor and a glycosylated $\sim 25-\mathrm{kDa}$ mature Lcn2, but only the latter is secreted $[6,11]$. Lcn2 is also secreted by various epithelia, including the kidney; however its function there is less clear. It has been proposed that holo-Lcn2 stimulates epithelial growth and differentiation, and promotes repair and regeneration of damaged epithelia, e.g. during acute kidney injury [12], (reviewed in [13]). A recent study has implicated Lcn2 secretion from collecting duct (CD) $\alpha$-intercalated cells as a bacteriostatic defense mechanism against pathogenic bacteria in the urine [14]. Secretion was induced by the bacterial wall component lipopolysaccharide (LPS) within the renal collecting duct $(\mathrm{CD})$ via Toll-like cell surface receptor-4 (TLR-4) activation [14], likely involving NF-kB activation [15].

A receptor for Lcn2 (Lcn2-R/Slc22a17/24p3-R) has been cloned ( $\mathrm{MM} \sim 60 \mathrm{kDa}$ ) [8] and is expressed in multiple epithelial tissues, including the renal nephron. In the rodent kidney, Lcn2-R was detected apically in distal convoluted tubules and CD [16]. The most abundant localization of Lcn2-R in the kidney is the medulla [16] thus strongly implying a relationship with the hyperosmolar environment. Experimental evidence in cultured cells and in vivo $[16,17]$ indicates that Lcn2-R is a high-affinity protein receptor in the distal nephron. The data suggest that physiologically it is responsible for exhaustive protein reabsorption to clear the final urine from proteins, or to limit losses associated with proteinuric renal diseases [18]. In fact, Lcn2-R affinity for Lcn2 is $\sim 1000 \mathrm{x}$ higher $\left(K_{D} \sim 90 \mathrm{pM}\right)[19]$ than that of megalin $\left(K_{D} \sim 60 \mathrm{nM}\right)$ [20], the high-capacity receptor for endocytic reabsorption of filtered proteins in the proximal tubule [21].

Little is known about the physiological regulation of Lcn2-R and Lcn2 expression, which may be interlinked. Inverse co-regulation of Lcn 2 and Lcn2-R was observed by Green and coworkers $[8,9]$ who showed in murine leukemia cell models that the oncogene BCR-ABL increases Lcn 2 and represses Lcn2-R expression. Lcn2 and Lcn2-R are also co-regulated by the $\mathrm{Wnt} / \beta$-catenin pathway, which is involved in survival, growth and proliferation [22] and can be activated by hyperosmotic stress [23, 24]. In murine mammary epithelial C57MG cells, Ziegler et al. $[25,26]$ demonstrated that overexpression of Wnt-1 decreases Lcn2. Furthermore, Wnt-1 activity affected splicing of Lcn2-R transcripts, indicating co-regulation of Lcn2 and Lcn2-R expression [25].

The aim of the study was to determine the role of osmolarity/tonicity and $\mathrm{Wnt} / \beta$-catenin signaling on Lcn2 and Lcn2-R expression in rat primary IMCD and mouse (m)IMCD3 cells exposed to norm- and hyperosmotic/-tonic media. The data indicate that Lcn2-R upregulation and Lcn2 downregulation in hyperosmotic/ -tonic media is mediated by activation of $\mathrm{Wnt} / \beta$-catenin signaling and protects IMCD cells against Lcn2-induced damage and death. In contrast, LPS upregulates Lcn2 but downregulates Lcn2-R in IMCD cells, which may also be cytoprotective in the context of urinary tract infections (UTIs). The significance of the inverse regulation of Lcn2-R and Lcn2 as a protective measure in the context of normosmotic conditions and/or bacterial infection is discussed. 


\section{Methods}

\section{Materials}

Recombinant $\mathrm{Fe}^{3+}$-free rat apo-Lcn2 was from Enzo Life Sciences (ALX-201-417-C050). Lipopolysaccharides from Escherichia coli (E coli) (cat. \# L3129) were from Sigma-Aldrich. All other reagents were purchased at the highest purity grade possible. Materials were dissolved either in water, ethanol, or dimethyl sulfoxide (DMSO). In control experiments, solvents were added to cells at concentrations not exceeding $0.2 \%$. Antibodies are listed in Table 1.

\section{Culture of mIMCD3 cells and transient transfections}

The mouse mIMCD3 cell line [27] was obtained from ATCC (cat. \# ATCC CRL-2123). Cells (passage numbers 20-30) were cultured in Dulbecco's modified Eagle's medium (DMEM)/F-12 (1:1) (Gibco cat. \# 31330) supplemented with $10 \%$ fetal bovine serum (FBS), $50 \mathrm{U} / \mathrm{ml}$ penicillin, and $50 \mu \mathrm{g} / \mathrm{ml}$ streptomycin. Cells were cultured in $25 \mathrm{~cm}^{2}$ standard tissue culture flasks (Sarstedt) at $37^{\circ} \mathrm{C}$ in a humidified incubator with $5 \% \mathrm{CO}_{2}$ and were passaged twice a week upon reaching $90 \%$ confluency.

For transient transfections, 1.0-1.3 x 10 $0^{5}$ mIMCD3 cells were seeded in 6-well plates. After $24 \mathrm{~h}$, cells were $\sim 40 \%$ confluent and transfected with $25 \mathrm{nM} \beta$-catenin (Gene name: Ctnnb1) SMART-pool siRNA (Dharmacon cat. \# L-040628-00-0005) or siRNA duplex negative control (Eurogentec cat. \# SR-CL000-005) in standard culture medium without antibiotics using Lipofectamine RNAiMAX (Thermo Fisher Scientific) according to manufacturer's instructions. After $6 \mathrm{~h}$, medium was exchanged to 300 and $600 \mathrm{mosmol} / \mathrm{l}$ media with or without FBS and incubated for up to $48 \mathrm{~h}$.

\section{Isolation and culture of rat primary IMCD cells}

Inner medullary collecting duct (IMCD) cells were prepared from inner medullas including papilla of sacrificed
Wistar rats (license \# 84-02.05.20.11.256), as previously described [28]. Briefly, the inner medullas including papilla of sacrificed Wistar rats were removed, cut into small pieces, and digested in phosphate-buffered saline (PBS) containing $0.2 \%$ hyaluronidase (Sigma) and $0.2 \%$ collagenase type CLS-II (Sigma) at $37^{\circ} \mathrm{C}$ for $90 \mathrm{~min}$. Cells were centrifuged at $450 \mathrm{x} g$, resuspended in PBS and centrifuged once more. Cells were seeded on glass coverslips coated with collagen type IV (Becton-Dickinson) at a density of $10^{5}$ cells $/ \mathrm{cm}^{2}$ and cultured in DMEM containing $100 \mathrm{IU} / \mathrm{ml}$ penicillin, $100 \mu \mathrm{g} / \mathrm{ml}$ streptomycin, $0.2 \%$ glutamine, $1 \%$ nonessential amino acids and $1 \%$ ultroser $\mathrm{G}$ (BioSepra Inc.) in an $8 \% \mathrm{CO}_{2}$ atmosphere.

\section{Osmolarity experiments}

Unless otherwise indicated, in osmolarity experiments, cell lines were cultured for $24 \mathrm{~h}$ in standard culture medium after plating before osmolarity was adjusted to $600 \mathrm{mos}$ $\mathrm{mol} / \mathrm{l}$ by the addition of $100 \mathrm{mmol} / \mathrm{l} \mathrm{NaCl}$ and $100 \mathrm{mmol} / \mathrm{l}$ urea from $3 \mathrm{M}$ and $6 \mathrm{M}$ stock solutions to normosmotic/ -tonic culture media (300 mosmol/l), respectively, and cultured in normo-/hyperosmotic medium for up to $72 \mathrm{~h}$ (for simplification the term "osmolarity" henceforth refers to osmolarity and tonicity). Proliferation was reduced in mIMCD3 cells exposed to $600 \mathrm{mosmol} / \mathrm{l}$ media (Additional file 1: Figure S1A) along with initial decrease of cell cycle and proliferation genes $M y c$ and Ccnd1 mRNA, which returned to normal (Ccnd1) or was even elevated $(M y c)$ at $72 \mathrm{~h}$ (Additional file 1: Figure S1B). This confirms that a hyperosmotic environment induces cell stress with cell cycle arrest and inhibition of proliferation [4]. Reactive adaptation to hyperosmolarity was supported by up-regulation of $\mathrm{Na}^{+} / \mathrm{K}^{+}$-ATPase at $72 \mathrm{~h}$ (Additional file 1: Figure S1C, bottom; Additional file 1: Figure S1D, lanes 2 and 4), which is known to contribute to osmoprotection of primary IMCD [29] and mIMCD3 cells [30].

Table 1 Primary antibodies

\begin{tabular}{|c|c|c|c|c|c|}
\hline Immunogen & Host species & Manufacturer & Catalog \# & Application & Dilution \\
\hline Len2 (rat) & goat & RD Systems & AF3508 & IB & $1: 200-300$ \\
\hline Len2 (mouse) & rabbit & Abcam & Ab63929 & IF & $1: 250-500$ \\
\hline Len2-R (C-term) (rat) & rabbit & Immunoglobe & $\lg -1086$ & IB & $1: 250-2,000$ \\
\hline Len2-R (N-term) (rat) & rabbit & Immunoglobe & $\lg -1095$ & IF & $1: 100-1000$ \\
\hline$\beta$-actin & mouse & Sigma-Aldrich & A5316 & IB & $1: 20,000$ \\
\hline$\beta$-catenin (mouse) & mouse & BD Biosciences & 610153 & $\mathrm{IB}$ & $1: 2,000-5,000$ \\
\hline GSK-3ß (rat) & mouse & BD Biosciences & 610201 & IB & $1: 500$ \\
\hline Phospho-GSK-3 $\beta$ (Ser9) (human) & rabbit & Cell Signaling Technology & 9336 & IB & $1: 500$ \\
\hline $\mathrm{Na}^{+}, \mathrm{K}^{+}$-ATPase a1-subunit (human) & rabbit & Cell Signaling Technology & $3010 S$ & $\begin{array}{l}\text { IB } \\
\text { IF }\end{array}$ & $\begin{array}{l}1: 250-500 \\
1: 100\end{array}$ \\
\hline FLAG-M2 & mouse & Sigma-Aldrich & F3165 & IB & $10 \mu \mathrm{g} / \mathrm{ml}$ \\
\hline
\end{tabular}

$I B=$ immunoblotting. $I F=$ immunofluorescence 
For primary cells, osmolarity was adjusted to 600 mos$\mathrm{mol} / \mathrm{l}$ by addition of $100 \mathrm{mmol} / \mathrm{l} \mathrm{NaCl}$ and $100 \mathrm{mmol} / \mathrm{l}$ urea to normosmotic culture media in order to preferentially select for IMCD cells. After $24 \mathrm{~h}$, the medium was replaced by normosmotic or hyperosmotic media by adding the appropriate concentration of osmolytes (no additions for 300 mosmol/l and or mmol/l $\mathrm{NaCl}$ and $100 \mathrm{mmol} / \mathrm{l}$ urea for $600 \mathrm{mosmol} / \mathrm{l}$ ) and experiments were performed one week later.

\section{Plasmid construction and generation of $\mathrm{CHO}-\mathrm{K} 1$ cells stably expressing LCN2-R}

The plasmid encoding C-terminally FLAG-tagged full-length human (h)LCN2-R isoform A (GenBank accession number NM_020372.3) was generated by replacing the sequence encoding rLcn2R with hLCN2-R isoform A by restriction digestion and ligation (Ligate-IT, VWR/Affymetrix) in the plasmid previously described [31] (kindly provided by Dr. N. Coudevylle, Max F. Perutz Laboratories, University of Vienna, Austria). The sequence was then converted to hLCN2-R isoform B (GenBank accession number NM_016609.4) (which - in preliminary experiments - appeared to be more efficiently expressed in the plasma membrane; N.A.W. \& F.T., unpublished observations) by site-directed mutagenesis (QuikChange II Site-Directed Mutagenesis Kit; Agilent Technologies) as per manufacturer's instructions, using the following primers: forward 5'-CTGG GCCTGTGGGATTATCTGAACGAGGCTGCC-3', reverse 5'-GGCAGCCTCGTTCAGATAATCCCACAGGC

CCAG-3, 18 cycles of $30 \mathrm{~s}$ at $95^{\circ} \mathrm{C}, 60 \mathrm{~s}$ at $55^{\circ} \mathrm{C}$, and $8 \mathrm{~min}$ at $68^{\circ} \mathrm{C}$. All constructs were verified by sequencing.

To generate stable $\mathrm{CHO}-\mathrm{K} 1$ clones, cells seeded at $2.5 \times 10^{4}$ cells $/ \mathrm{cm}^{2}$ were transfected $24 \mathrm{~h}$ later with hLCN2-R-FLAG isoform B construct, or empty pcDNA3.1 vector using Lipofectamine LTX Plus (Thermo Fisher) according to manufacturer's instructions, selected for $>8$ weeks under $600 \mu \mathrm{g} / \mathrm{ml}$ G418 with medium change every 2-3 days, and passaged upon reaching confluency. Stable clones were further selected with G418 by two rounds of serial dilution and plating at dilutions corresponding to a density of about $0.5,3$ and 10 cells / well in 96-well plates. Wells containing individual colonies were controlled by microscopy and hLCN2-R-FLAG isoform B expression was verified by reverse transcriptase (RT) PCR (Additional file 2: Figure S2A) and immunoblotting (Additional file 2: Figure S2B).

\section{Cell viability assay of mIMCD3 and CHO-K1 cells}

$1.5 \times 10^{4}$ mIMCD3 cells were seeded per well in 48-well plates and cultured for $24 \mathrm{~h}$ to obtain $\sim 60 \%$ confluency. Stably transfected $\mathrm{CHO}-\mathrm{K} 1$ cells were plated at $9 \times 10^{3}$ cells $/ \mathrm{cm}^{2}$ for pcDNA3.1 cells (clone A2) and $1.3 \times 10^{4}$ cells $/ \mathrm{cm}^{2}$ for hLCN2-R-FLAG isoform B cells (clone
D6.D10) to compensate for differences in doubling time. Medium was replaced every $24 \mathrm{~h}$ with fresh 600 mos$\mathrm{mol} / \mathrm{l}$ culture medium $\pm 5 \mu \mathrm{g} / \mathrm{ml}$ LPS [32]. After treatments, cell viability was determined by the MTT test, as previously described [33].

\section{Cell death assays of rat primary IMCD cells}

Lactate dehydrogenase release was measured using the CytoTox-Fluor cytotoxicity assay (Promega), according to manufacturer's protocols.

\section{RNA extraction, cDNA synthesis and RT-PCR}

Isolation of total RNA, synthesis of $\mathrm{CDNA}$ and PCR reactions were performed as previously described [34]. PCR reactions were performed using specific primers and cycling protocols (see Table 2). Gel documentation and densitometry analysis were performed using Image Lab Software version 5.2 (Bio-Rad Laboratories) with correction for loading with the housekeeping gene Gapdh.

\section{Quantitative PCR of mIMCD3 cells}

RNA extraction and cDNA synthesis were performed as described for the RT-PCR protocol. Resulting cDNA was diluted 1:10 with 1/10 TE buffer. Primers were designed using PrimerBLAST software (NCBI) and/or taken from the literature. The primers were obtained from Eurofins Genomics and primer efficiency was assessed using serially diluted mixed cDNAs (see Table 3). Quantitative PCR (qPCR) was performed essentially as previously described [35] in a StepOnePlus Real-Time PCR System (Applied Biosystems) using KAPA SYBR FAST qPCR Master Mix Universal and ROX reference dye (PEQLAB Biotechnologie). The cycling conditions were activation at $95{ }^{\circ} \mathrm{C}$ for $1 \mathrm{~min}, 40-50$ cycles of $95^{\circ} \mathrm{C}$ for $3 \mathrm{~s}$ and $60^{\circ}$ $\mathrm{C}$ for $30 \mathrm{~s}$ with melt curve analysis to check amplification specificity of the product. Gene expression levels were calculated according to the $2^{-\Delta C q}$ method relative to the sample with the highest expression (minimum $C q$ ) [36]. The data obtained were normalized to the expression of three stable reference genes: Gapdh, Actb, and $B 2 m$.

\section{Quantitative PCR of rat primary IMCD cells}

Total RNA was isolated from rat primary IMCD cells using a RNeasy-kit (Qiagen) and cDNA was synthesized according to standard protocols using SuperScript II Kit (Invitrogen). Quantitative PCR (qPCR) was performed using SYBR Green PCR Master Mix on the ABI PRISM 7900 Sequence Detection System. All qPCR instruments and reagents were purchased from Thermo Fisher Scientific (Darmstadt, Germany). Relative gene expression values were evaluated with the $2^{-\Delta \Delta C t}$ method using Gapdh as reference (ref PMID: 11846609). The primer pairs used were for rat Gapdh (GenBank accession 


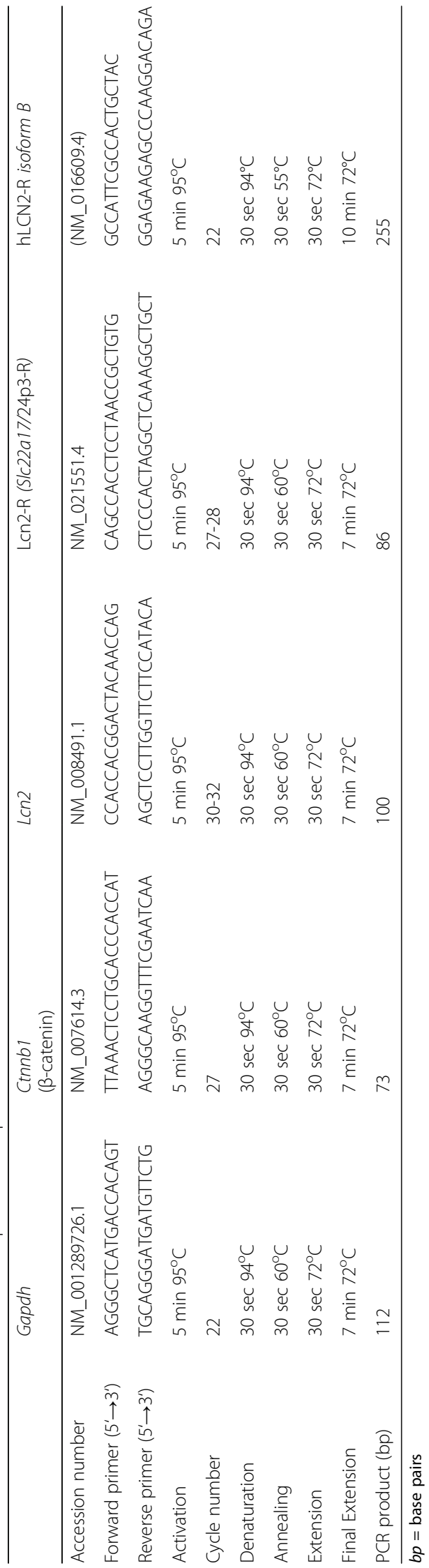




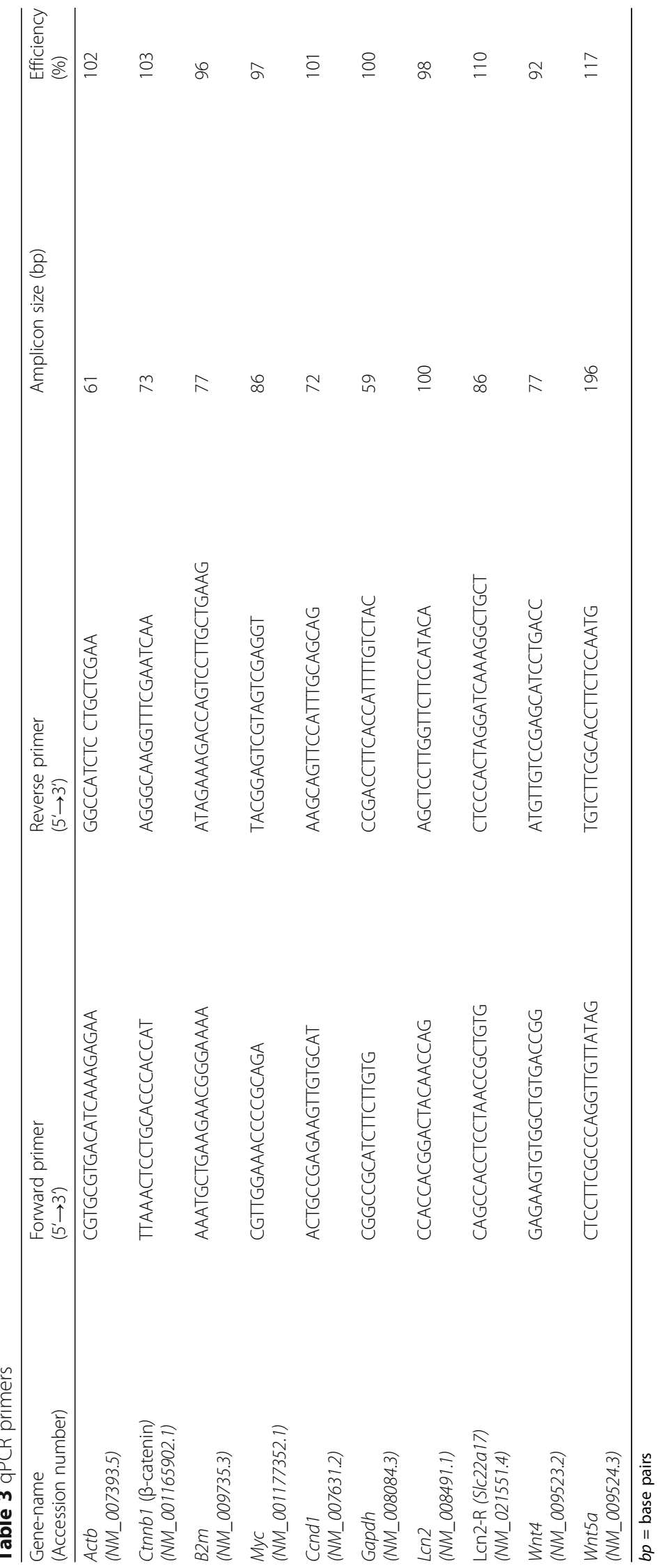


number NM_017008.4): forward 5'CATCAACGA CCCCTTCATTGAC-3', reverse 5'-ACTCCACGA CATACTCAGCACC-3' and for rat Lcn2 (GenBank accession number NM_130741.1) forward 5'-GGGC TGTCGCTACTGGATCAG-3', reverse 5'-CGTACAGGG TGACTTTGAAGTAC -3'.

\section{Determination of Lcn2 secretion}

Lcn 2 secretion by mIMCD3 and CHO-K1 cells was detected by immunoblotting using recombinant rodent Lcn2 to generate a standard curve. Supernatants from 2 wells of a 6 well plate were pooled ( $3 \mathrm{ml}$ total volume) for each treatment and concentrated at room temperature (RT) to a final volume of $30-50 \mu \mathrm{l}$ using Vivaspin 500 Centrifugal Concentrators $(10 \mathrm{kDa}$ molecular weight cut-off; cat. \# VS0102, Sartorius). Volumes were adjusted, combined with 3X Laemmli buffer and used for immunoblotting. Lcn2 immunoblot signals from supernatants were normalized to cell numbers determined using a Countess II FL Automated Cell Counter (Thermo Fisher). Supernatants from stably transfected $\mathrm{CHO}-\mathrm{K} 1$ cells were immunoblotted either non-concentrated or concentrated only by $\sim 4$-fold to avoid interference by FBS contamination.

Lcn2 in supernatants of primary rat IMCD cells was detected using the Rat Lcn2 DuoSet ELISA (R\&D Systems) according to manufacturer's protocol.

\section{Isolation of plasma membranes from mIMCD3 and $\mathrm{CHO}-$ K1 cells}

$1.25 \times 10^{6}$ mIMCD3 cells were seeded into $175 \mathrm{~cm}^{2}$ culture flasks and grown for $24 \mathrm{~h}$ before medium was replaced by fresh normosmotic or hyperosmotic media and cultured for additional $72 \mathrm{~h}$. Plasma membranes (PM) from transiently transfected $\mathrm{CHO}-\mathrm{K} 1$ cells were obtained following G418 selection as previously described [16] with the following modification: After cell homogenization, unbroken cells, nuclei, and large debris were removed by centrifugation at $1000 \mathrm{x} g$ for $10 \mathrm{~min}$. PM enrichment was verified by immunoblotting and showed an $\sim 20$-fold enrichment in $\mathrm{Na}^{+}, \mathrm{K}^{+}$-ATPase.

\section{Immunoblotting}

Sodium dodecyl sulfate polyacrylamide gel electrophoresis (SDS-PAGE) and immunoblotting were performed according to standard procedures by wet transfer, as described earlier [16], with the exception of Lcn2 immunoblots that were electroblotted by rapid semi-dry transfer (Bio-Rad Laboratories Trans-Blot Turbo). Cells were washed in PBS, scraped and homogenized by sonication (Branson Digital Sonifier) in isosmotic sucrose buffer supplemented with protease inhibitor cocktail. Protein concentration was determined by the Bradford method [37], using bovine serum albumin (BSA) as standard. For the analysis of phosphorylated proteins, cells were washed once with PBS and scraped into lysis buffer containing phosphatase inhibitors as previously described [38], and protein was determined by the method of Lowry et al. [39]. Equal amounts of protein $(2.5-50 \mu \mathrm{g})$ were subjected to 6 or 15\% SDS-PAGE and immunoblotted. Primary antibodies and their dilutions are listed in Table 1. For anti-phosphorylation and Lcn 2 antibodies, dilution of primary antibodies was performed in 5\% BSA. Horseradish peroxidase-conjugated secondary antibodies were purchased from Santa Cruz Biotechnology, Inc. or GE Healthcare and used at 1:2,500 - 1:30,000 dilutions. Densitometry analysis was performed using ImageJ software [40].

\section{Surface expression of Lcn2-R in rat primary IMCD cells by flow cytometry}

Rat IMCD cells were dissociated using Accutase ${ }^{\circ}$ solution (Sigma) and collected by centrifugation ( $5 \mathrm{~min}, 500 \mathrm{x}$ ). The supernatant was discarded and cells were washed with PBS and centrifuged once more $(5 \mathrm{~min}, 500 \mathrm{x}$ ). The cell pellet was resuspended in $1 \%$ BSA in PBS $(1 \%$ BSA-PBS) with anti-N-terminal rodent Lcn2-R polyclonal rabbit IgG (see Table 1) (1:200 dilution) and incubated for $45 \mathrm{~min}$ at RT. The cells were collected by centrifugation, washed twice with PBS and incubated for $30 \mathrm{~min}$ at RT with PBS containing a 1:500 dilution of secondary Alexa Fluor 488-conjugated goat anti-rabbit IgG. Cells were washed once in PBS, resuspended in FACSFlow buffer (BD Biosciences) and analyzed on a FACS Calibur flow cytometer (BD Biosciences) using the CellQuest Pro software (BD Biosciences).

\section{Immunofluorescence staining and microscopy}

Immunofluorescence microscopy of mIMCD3 cells (1.0-4.0 x $10^{4}$ cells / well on glass coverslips, $40-50 \%$ confluency after $24 \mathrm{~h}$ ) was either performed in non-permeabilized cells to detect surface expression of $\mathrm{Na}^{+} / \mathrm{K}^{+}$-ATPase and Lcn2-R, or in permeabilized cells to detect cellular Lcn2 and Lcn2-R expression. Surface staining was performed at $4^{\circ} \mathrm{C}$ whereas staining of permeabilized cells was carried out at RT.

For surface staining, cells were blocked with 1\% BSA-PBS for $1 \mathrm{~h}$ before incubation with primary antibody in 1\% BSA-PBS for $2 \mathrm{~h}$. Cells were then incubated with secondary Cy3-coupled donkey anti-rabbit IgG (1:600; cat. \# 711-165-152, Jackson ImmunoResearch) or Alexa Fluor 488-conjugated goat anti-rabbit IgG (1:500; cat. \# A-11008, Thermo Fisher) for 1 hour. Cells were fixed with $4 \%$ paraformaldehyde (PFA) in PBS for 30 $\mathrm{min}$ at RT. Nuclei were counterstained with $0.8 \mu \mathrm{g} / \mathrm{ml}$ Hoechst 33342 for $5 \mathrm{~min}$. Coverslips were embedded with DAKO fluorescent mounting medium, and images 
$\mathbf{A}$

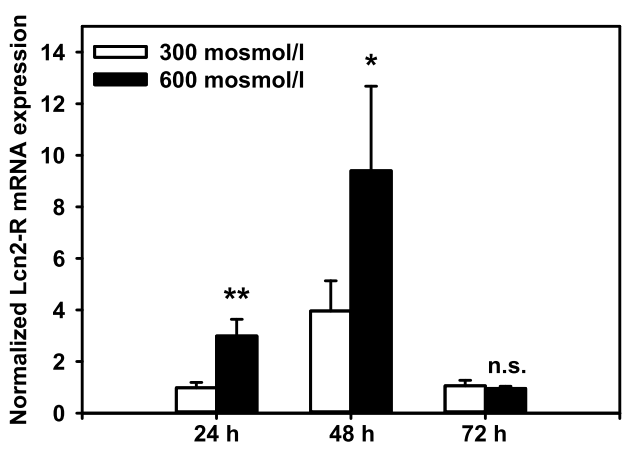

C

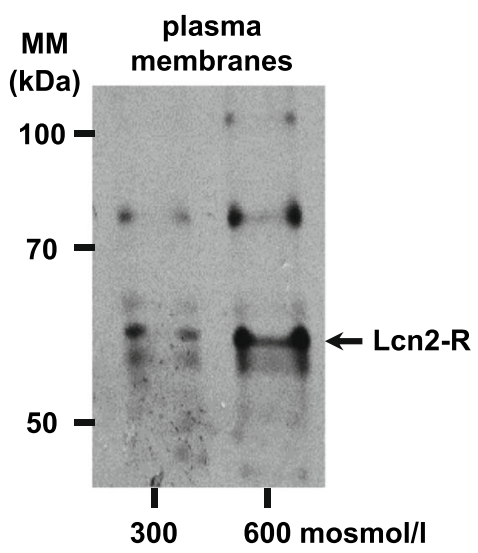

D
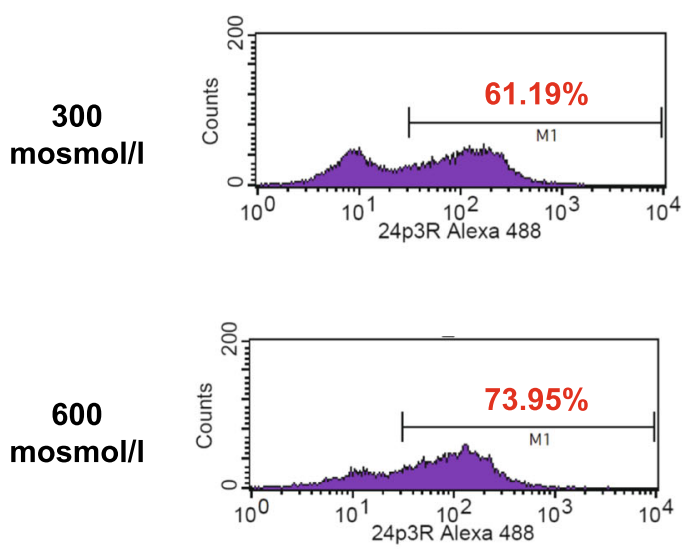

B

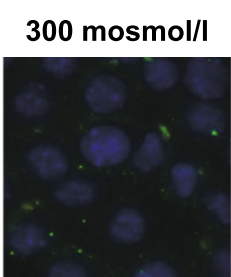

$600 \mathrm{mosmol} / \mathrm{l}$
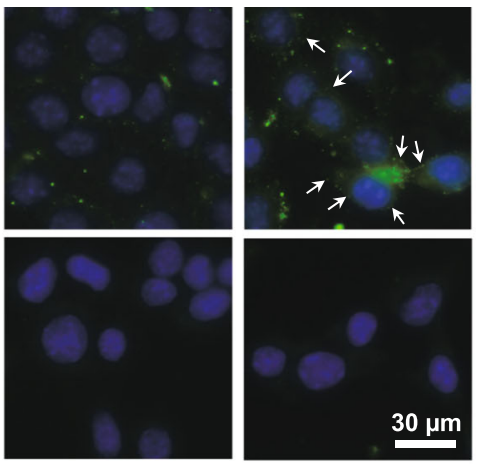

Len2-R

negative

control

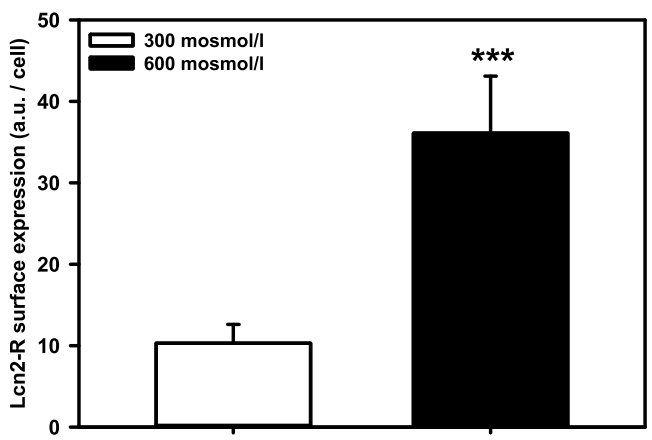

E

$300 \mathrm{mosmol} / \mathrm{l}$

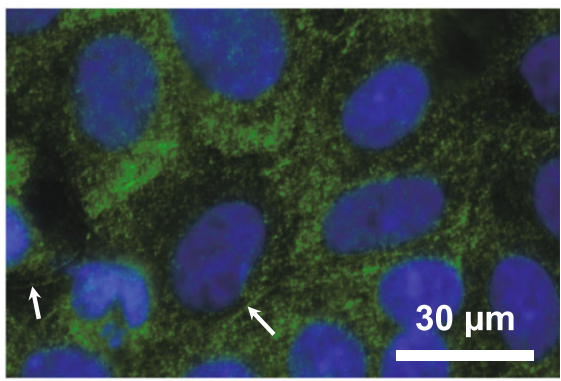

$600 \mathrm{mosmol} / \mathrm{l}$

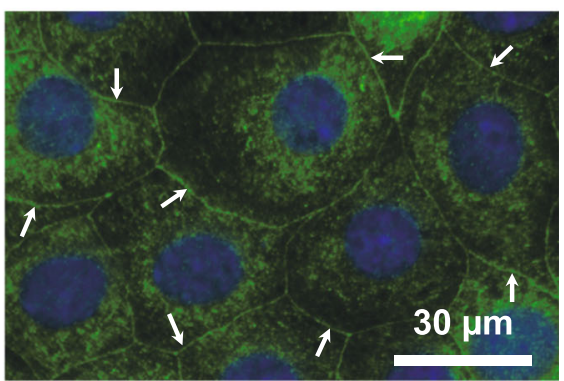

Fig. 1 (See legend on next page.) 
(See figure on previous page.)

Fig. 1 Hyperosmolarity increases Lcn2-R expression in mIMCD3 cells and primary rat IMCD cells. a Expression levels of Lcn2-R mRNA by qPCR in mIMCD3 cells exposed to 300 (normosmolarity/-tonicity) or 600 mosmol/ (hyperosmolarity/-tonicity) for 24 - 72 h. Means \pm SEM of 4-5 experiments are shown. The data obtained were normalized to the expression of the reference genes glyceraldehyde-3-phosphate dehydrogenase (Gapdh), $\beta$-actin (Actb), and $\beta 2$-microglobulin $(B 2 m)$. Statistical analysis compares the two osmotic conditions by unpaired $t$-test. n.s. $=$ not significant. $\mathbf{b}$ Surface expression of Lcn2-R in mIMCD3 cells exposed to norm- or hyperosmotic media for $72 \mathrm{~h}$. Lcn2-R was detected by live immunofluorescence microscopy of non-permeabilized cells using a Lcn2-R antibody directed against the extracellular N-terminus. Nuclei were counterstained with Hoechst 33342. Arrows indicate punctate staining along the plasma membranes of mIMCD3 cells. Statistical analysis shows means \pm SEM of 4 experiments and compares the two osmotic conditions by unpaired $t$-test. a.u. $=$ arbitrary units. $\mathbf{c}$ Immunoblotting of plasma membranes (PM) of mIMCD3 cells grown for $72 \mathrm{~h}$ in norm- or hyperosmotic media. Lcn2-R is expressed in PM at the expected molecular mass of $\sim 62 \mathrm{kDa}$. The experiment is representative of three similar ones. $\mathbf{d}$ Histograms of Lcn2-R surface expression in rat primary IMCD cells exposed to 300 or 600 mosmol// for 7 days. Lcn2-R was determined by flow cytometry using a Len2-R antibody directed against the extracellular N-terminus. The experiment is representative of three similar ones. e Expression of Lcn2-R in rat primary IMCD cells cultured in norm- or hyperosmotic media for a total of 7 days. Lcn2-R was detected by immunofluorescence microscopy of permeabilized cells using an Lcn2-R antibody directed against the N-terminus. Arrows indicate LCn2-R staining along the plasma membranes of rat primary IMCD cells. Nuclei were counterstained with DAPI. The experiment is representative of three similar ones.

were acquired and fluorescence was quantified as described elsewhere [41].

For cellular Lcn2 or Lcn2-R staining, cells were fixed with 4\% PFA in PBS for $10 \mathrm{~min}$, permeabilized with $1 \%$ SDS in PBS for $5 \mathrm{~min}$, and blocked with 1\% BSA-PBS for $40 \mathrm{~min}$. Primary antibodies diluted in 1\% BSA-PBS were incubated for $2 \mathrm{~h}$. Subsequent steps were identical to surface staining procedures.

For $\beta$-catenin siRNA transfected cells, 2500 cells/well were plated on glass coverslips in 24-well plates and grown for $72 \mathrm{~h}$ to reach a confluency of $30-40 \%$. Immunostaining of permeabilized mIMCD3 cells for Lcn2-R was performed $48 \mathrm{~h}$ after transfection essentially as described above, but with the following modifications: Cells were fixed with 4\% PFA in PBS for $30 \mathrm{~min}$ and permeabilized with $1 \%$ SDS in PBS for $20 \mathrm{~min}$.

Immunofluorescence staining of rat primary IMCD cells was performed as previously described [42]. Immunofluorescence images were captured with an epifluorescence Axiovert Z1 microscope and a digital camera AxioCamMR (Carl Zeiss).

\section{Statistics}

Unless otherwise indicated, the experiments were repeated at least three times with independent cultures. Means \pm SEM are shown, unless otherwise indicated. Statistical analysis using unpaired Student's $t$-test was carried out with GraphPad Prism v. 5.01 (GraphPad Software Inc., San Diego California USA). Results with $P<0.05$ were considered to be statistically significant. Significance levels were labelled in the Figures as follows: ${ }^{*}=P<0.05,{ }^{* *}=P<0.025$ and ${ }^{* * *}=P<0.01$.

\section{Results}

Hyperosmolarity increases expression of Lcn2-R in mIMCD3 and rat primary IMCD cells

Previous studies in rodent kidney have demonstrated highest abundance of Lcn2-R in the IMCD [16]. Hence, we hypothesized that Lcn2-R expression is linked to hyperosmolarity. qPCR of mIMCD3 cells exposed to 600 mosmol/l showed increased Lcn2-R mRNA expression at 24 and $48 \mathrm{~h}$ exposure, compared to normosmotic conditions (Fig. 1a). Surface expression of Lcn2-R in mIMCD3 cells was increased by $600 \mathrm{mosmol} / \mathrm{l}$ at $72 \mathrm{~h}$ (Fig. 1b, upper right panel), which was detected by staining of non-permeabilized cells using an antibody directed against the extracellular $\mathrm{N}$-terminus of rodent Lcn2-R where the punctate distribution represents specific receptor expression sites and/or receptor clusters on cellular plasma membranes [31]. Accordingly, immunoblotting of mIMCD3 cells showed increased Lcn2-R in PM of cells exposed to 600 mosmol/l for $72 \mathrm{~h}$ (Fig. 1c) at the expected molecular mass of $\sim 62 \mathrm{kDa}$ [8] (higher molecular weight bands could represent N-glycosylated Lcn2-R [31]). Similarly, primary rat IMCD cells cultured for 1 week in 600 mosmol/l showed increased surface expression of Lcn2-R, as determined by flow cytometry analysis of dissociated cells (Fig. 1d, bottom) and was verified by immunofluorescence microscopy of permeabilized primary rat IMCD cells (Fig. 1e, bottom), confirming induction of Lcn2-R gene expression. Similar observations were made for 900 mosmol/l media (data not shown). In contrast, Lcn2-R expression remained low under normosmotic conditions (Fig. 1) (see also model in Fig. 7a). Taken together, these data are consistent with in vivo medullary localization of Lcn2- $\mathrm{R}$ in the rat kidney [16] where it is elevated in a hyperosmotic environment.

Hyperosmolarity decreases expression of Lcn2 in mIMCD3 and rat primary IMCD cells

Next, the expression of the natural ligand of Lcn2-R, Lcn2 [8], was investigated under physiological, i.e. hyperosmotic, conditions for IMCD cells. Contrary to Lcn2-R, Lcn 2 mRNA expression was low in mIMCD3 cells exposed to hyperosmolarity for $24-72 \mathrm{~h}$ (Fig. 2a) but was increased at all time points investigated in normosmotic 


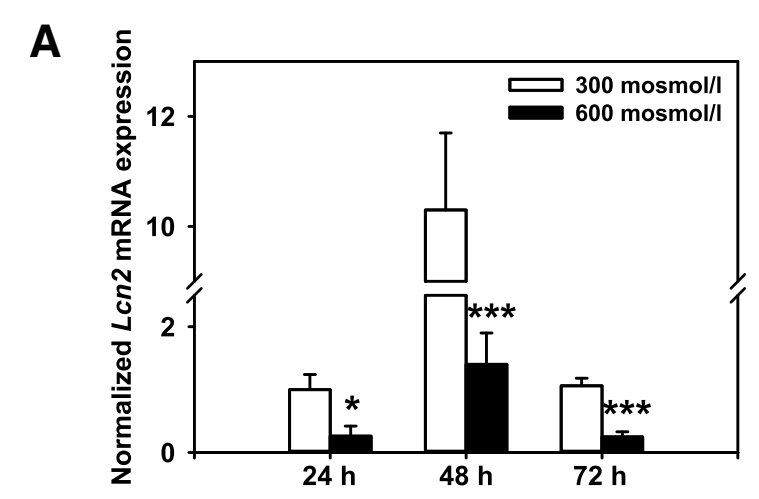

B

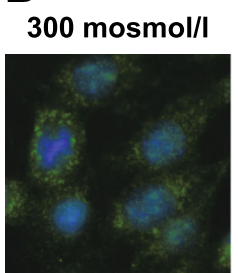

$600 \mathrm{mosmol} / \mathrm{l}$
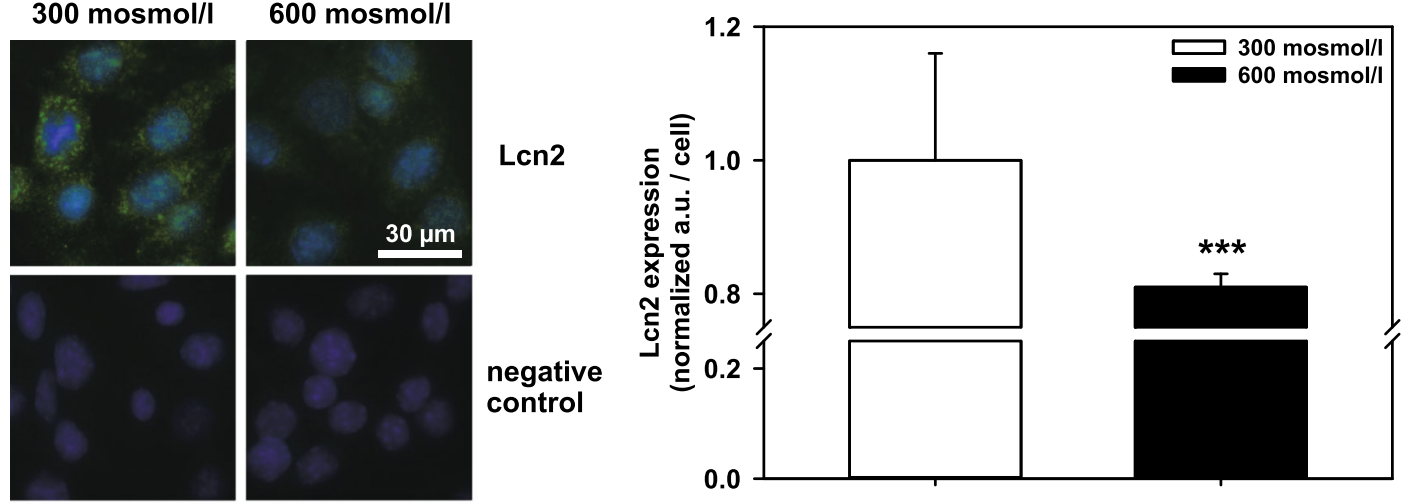

C

Len2 in cell culture medium

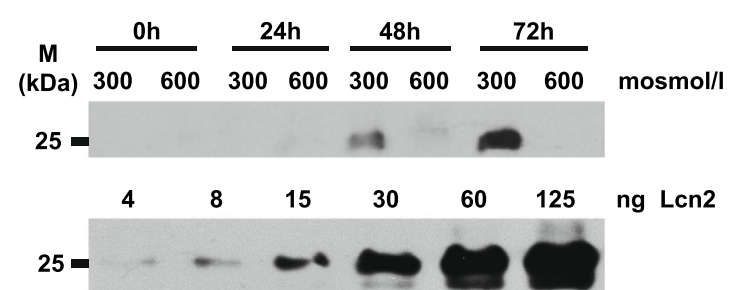

D

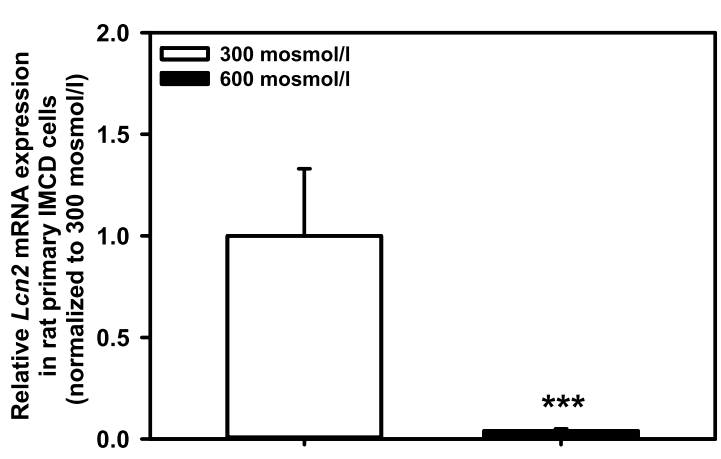

E
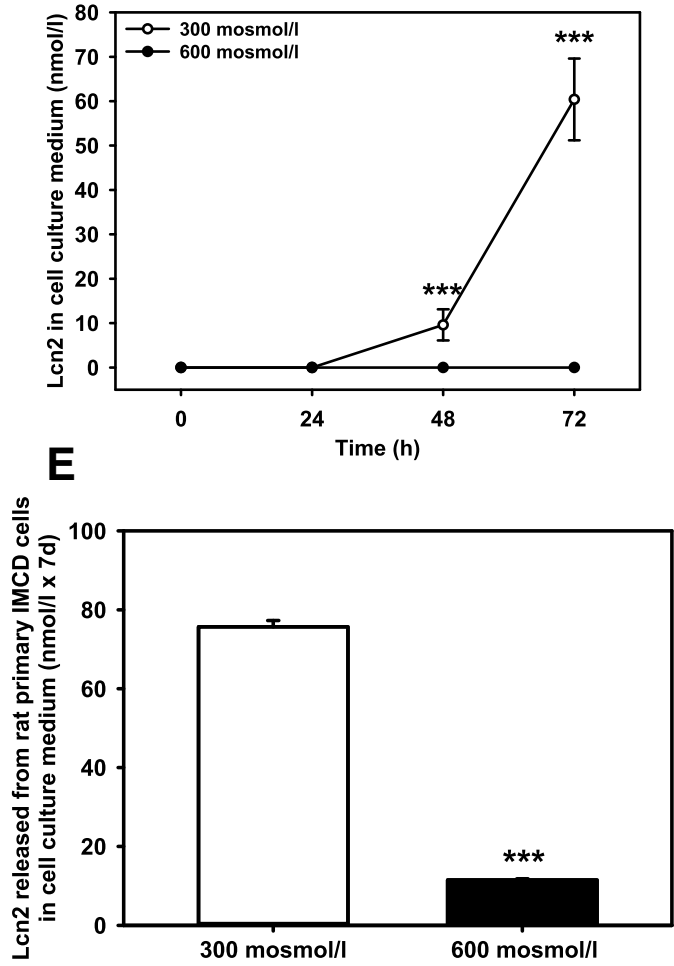

Fig. 2 (See legend on next page.) 
(See figure on previous page.)

Fig. 2 Hyperosmolarity decreases Lcn2 expression in mIMCD3 cells and rat primary IMCD cells. a Expression levels of Lcn2 mRNA by qPCR in mIMCD3 cells exposed to 300 or 600 mosmol/l for 24-72 h. The data obtained were normalized to the expression of the reference genes glyceraldehyde-3-phosphate dehydrogenase (Gapdh), $\beta$-actin (Actb), and $\beta 2$-microglobulin (B2m). Means \pm SEM of 4-5 experiments are shown. Statistical analysis compares the two osmotic conditions by unpaired $t$-test. $\mathbf{b}$ Expression of Len2 in mIMCD3 cells exposed to norm- or hyperosmotic media for $72 \mathrm{~h}$ was detected by immunofluorescence microscopy of permeabilized cells. Nuclei were counterstained with Hoechst 33342. Statistical analysis shows means \pm SEM of 3 experiments. Arbitrary units (a.u.) are normalized to normosmotic media (5.0 \pm 1.1 a.u.), and the two osmotic conditions are compared by unpaired $t$-test. c Kinetics of Lcn2 release from mIMCD3 cells exposed to norm- or hyperosmotic media for $72 \mathrm{~h}$. Lcn2 release was determined by immunoblotting. The upper blot is representative of 4 different experiments. To quantify experiments, Len2 standards were immunoblotted (lower blot). All immunoblot bands were analyzed by densitometry using ImageJ software and normalized to cell numbers. Lcn2 release $(\mathrm{nmol} / \mathrm{l})$ is plotted as means \pm SEM of 4 experiments. Statistical analysis compares the two osmotic conditions by unpaired t-test. $\mathbf{d}$ LCn2 gene expression in rat primary IMCD cells cultured in norm- or hyperosmotic media for 7 days. Relative Lcn2 gene expression was determined by GPCR. Means \pm SD of 3 experiments are plotted. Data are normalized to 300 mosmol// media and compares the two osmotic conditions by unpaired t-test. e Lcn2 release from rat primary IMCD cells one week after exposure to norm- or hyperosmotic media. LCn2 in cell culture medium was assayed by ELISA. Means \pm SEM of 7 experiments are shown and statistical analysis by unpaired $t$-test compares the two experimental conditions.

media (Fig. 2a). This was confirmed at the protein level by immunofluorescence microscopy of permeabilized cells (Fig. 2b, upper left panel; punctate staining likely represents intracellular vesicles). Paracrine/autocrine signaling is integral to Lcn 2 effects therefore Lcn2 secretion was probed by immunoblotting of cell supernatants. At $48 \mathrm{~h}$ and $72 \mathrm{~h}, \mathrm{Lcn} 2$ was detected in supernatants from mIMCD3 cells exposed to normosmotic media that progressively increased, implying continuous secretion, as opposed to cells in hyperosmotic media where no Lcn2 release into the medium was detected despite correction for cell number (Fig. 2c). These data were confirmed in rat primary IMCD cells where increased osmolarity for 1 week almost abolished Lcn2 mRNA expression (Fig. 2d) and Lcn2 release (Fig. 2e). Thus, reminiscent of observations made in other cell systems $[8,9]$, an inverse co-regulation of Lcn2 and Lcn2-R is governed by osmotic changes in IMCD cells (see also models in Fig. 7a and c).

\section{Apo-Lcn2 induces death of Lcn2-R expressing primary IMCD cells exposed to hyperosmolarity}

Several studies have demonstrated that $\mathrm{Fe}^{3+}$-free (apo-)Lcn2 induces death of Lcn2-R expressing cells $[8,9]$. This hypothesis was further tested in primary IMCD cells that expressed elevated Lcn2-R due to exposure to hyperosmotic media for 7 days (see Fig. 1d). Co-incubation with $15 \mu \mathrm{g} / \mathrm{ml}$ recombinant rat apo-Lcn 2 increased cell death, as indicated by augmented LDH leakage (Fig. 3). This Lcn2 concentration is ca. $10^{4}$ times higher than physiological urinary LCN2 concentrations in humans [43] and 20 -fold higher than urinary Lcn2 measured in patients with acute UTI [14]. However, apo-Lcn 2 may be competing with other components of the culture medium, such as albumin or transferrin, which are also ligands of the Lcn2-R [16], thus diminishing the efficacy of recombinant apo-Lcn2. These data indicate that (apo-)Lcn2 mediates death of cells expressing the
Lcn2-R, which is in line with previous concepts [44] and suggest that decreased expression of apo-Lcn2 when Lcn2-R is expressed may serve as a protective measure of IMCD cells against potential toxicity of autocrine/paracrine signaling of apo-Lcn2 in a physiological hyperosmotic environment (Figs. 1d-e, 2d-e) (see also model in Fig. 7b).

\section{Hyperosmolarity-induced Wnt/ $\beta$-catenin signaling mediates differential expression of Lcn2 and Lcn2-R in mIMCD3 cells}

The following lines of evidence suggested implication of Wnt/ $\beta$-catenin signaling in the hyperosmotic response: Wnt-1 transfected mammary epithelial cells display decreased $L c n 2$ expression and induction of a full-length transcript of Lcn2-R [25, 26], increased osmolarity activates Wnt signaling [23, 24], and osmolarity-induces an increase of $M y c$, a Wnt target gene (Additional file 1: Figure S1).

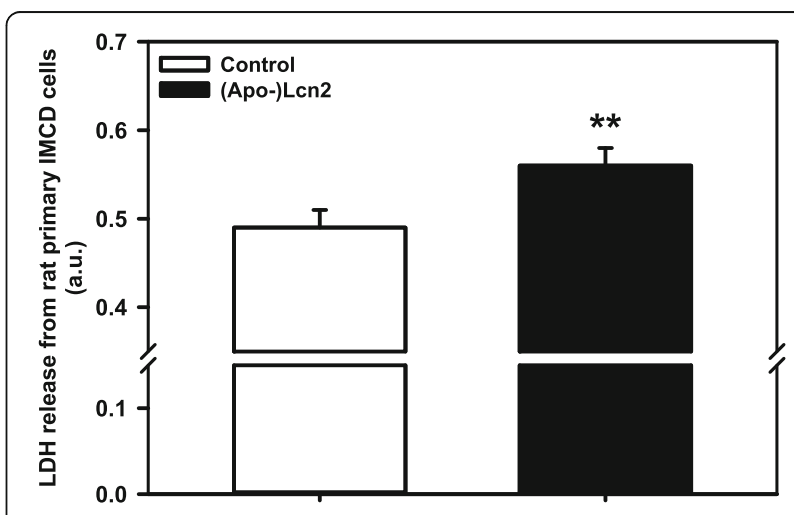

Fig. 3 Apo-Lcn2 induces death of rat primary IMCD cells exposed to hyperosmolarity. Cells were exposed to hyperosmotic media for 7 days to increase Lcn2-R expression and incubated with $15 \mu \mathrm{g} / \mathrm{ml}$ apo-Lcn2 for $24 \mathrm{~h}$. Cell death was determined by measuring lactate dehydrogenase $(\mathrm{LDH})$ release into the medium. Means \pm SEM of 4-6 experiments are shown and statistical analysis compares control versus apo-Lcn2 incubated cells by unpaired t-test. a.u. = arbitrary units 
Since Wnt ligands Wnt 4 and Wnt5a are highly expressed in mouse kidney [45], we tested the effect of hyperosmolarity on these Wnt ligands in mIMCD3 cells: $W n t 5 a$, but not Wnt4 mRNA was significantly increased by hyperosmotic media for 48 h (Fig. 4a). Furthermore, increased osmolarity was associated with increased $\beta$-catenin mRNA at $48 \mathrm{~h}$ (Fig. 4a) that precedes $M y c$ induction at $72 \mathrm{~h}$ (Additional file 1: Figure S1). Activation of the canonical Wnt signaling inhibits the kinase glycogen synthase kinase $3 \beta$ (GSK-3 $\beta$ ) in the $\beta$-catenin destruction complex, thereby preventing $\beta$-catenin phosphorylation and its proteasomal degradation [46]. Interestingly, GSK-3 $\beta$ phosphorylation at Ser9, which inactivates the kinase, was increased after exposure to hyperosmotic media for 24-72 h (Fig. 4b), confirming a previous study with HEK293 and mIMCD3 cells exposed to high $\mathrm{NaCl}$, in which inhibitory phosphorylation of GSK-3 $\beta$ at Ser9 (GSK-3 $\beta$-S9) activated TonEBP/OREBP/NFAT5 [47].
To determine whether Wnt/ $\beta$-catenin signaling is causally involved in the osmolarity-dependent regulation of Lcn2 and Lcn2-R expression, mIMCD3 cells were transfected with siRNA against $\beta$-catenin for $6 \mathrm{~h}$ prior to exposure to hyperosmotic media, which downregulated $\beta$-catenin mRNA after $24 \mathrm{~h}$ by $\sim 45 \%$ (Fig. $5 \mathrm{a}$; Additional file 3: Figure S3A), that was stable for up to $48 \mathrm{~h}$ (see Additional file 3: Figure S3B), and $\beta$-catenin protein after $24-48 \mathrm{~h}$ by $\sim 65 \%$ (Fig. $5 \mathrm{~b}$ and e). Silencing of $\beta$-catenin blunted Lcn2-R up- and Lcn2 downregulation elicited by high osmolarity at the mRNA level (Fig. $5 c)$. Similarly, the increase of Lcn2-R protein induced by high osmolarity was significantly attenuated by $\beta$-catenin silencing, as determined by immunofluorescence microscopy of mIMCD3 cells (Fig. 5d, compare upper and lower right panels). Analogous to neutrophils, two bands for Lcn2 were detected in whole mIMCD3 cell homogenates that represent the non-glycosylated $\sim 22-\mathrm{kDa}$ precursor and glycosylated

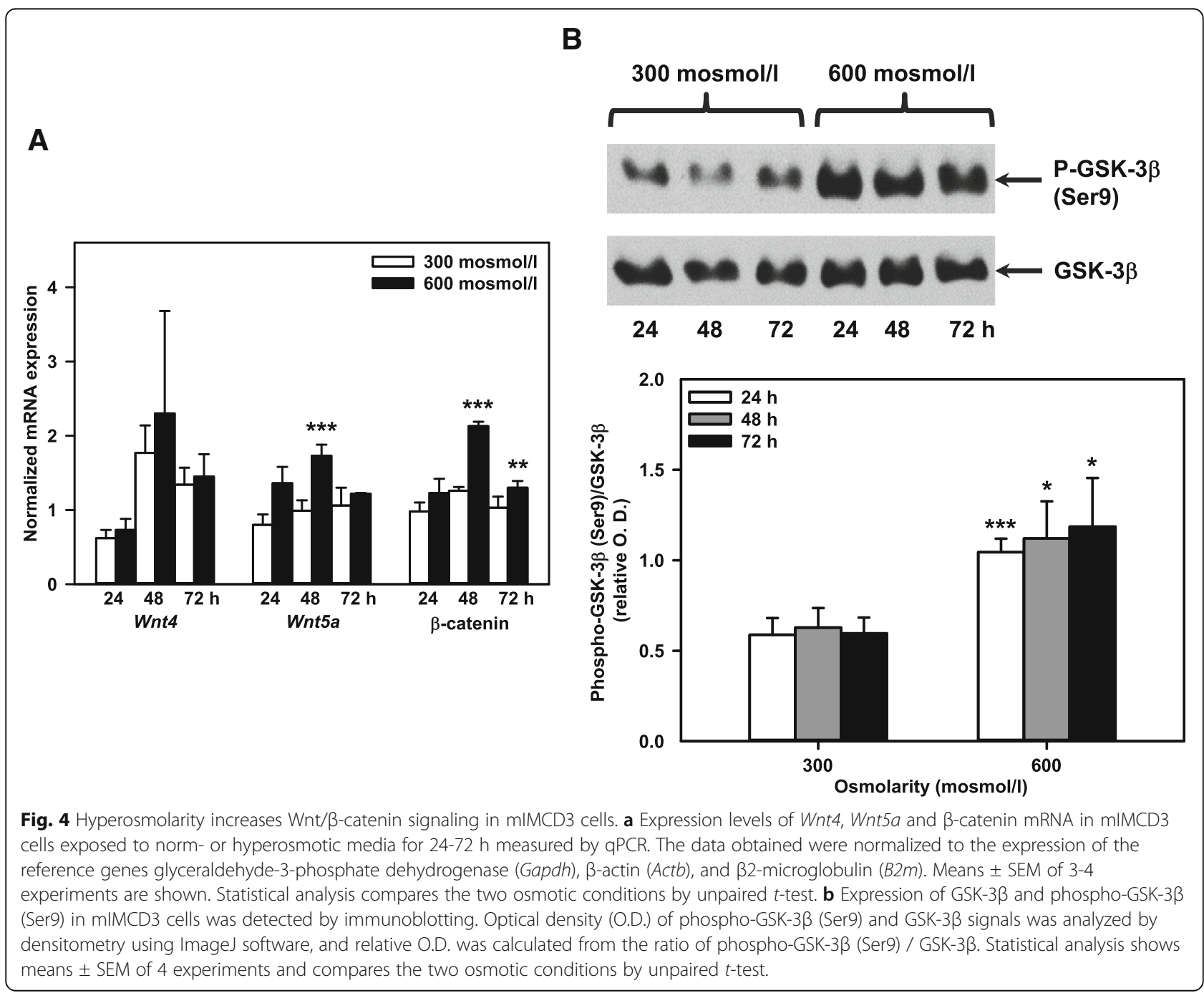




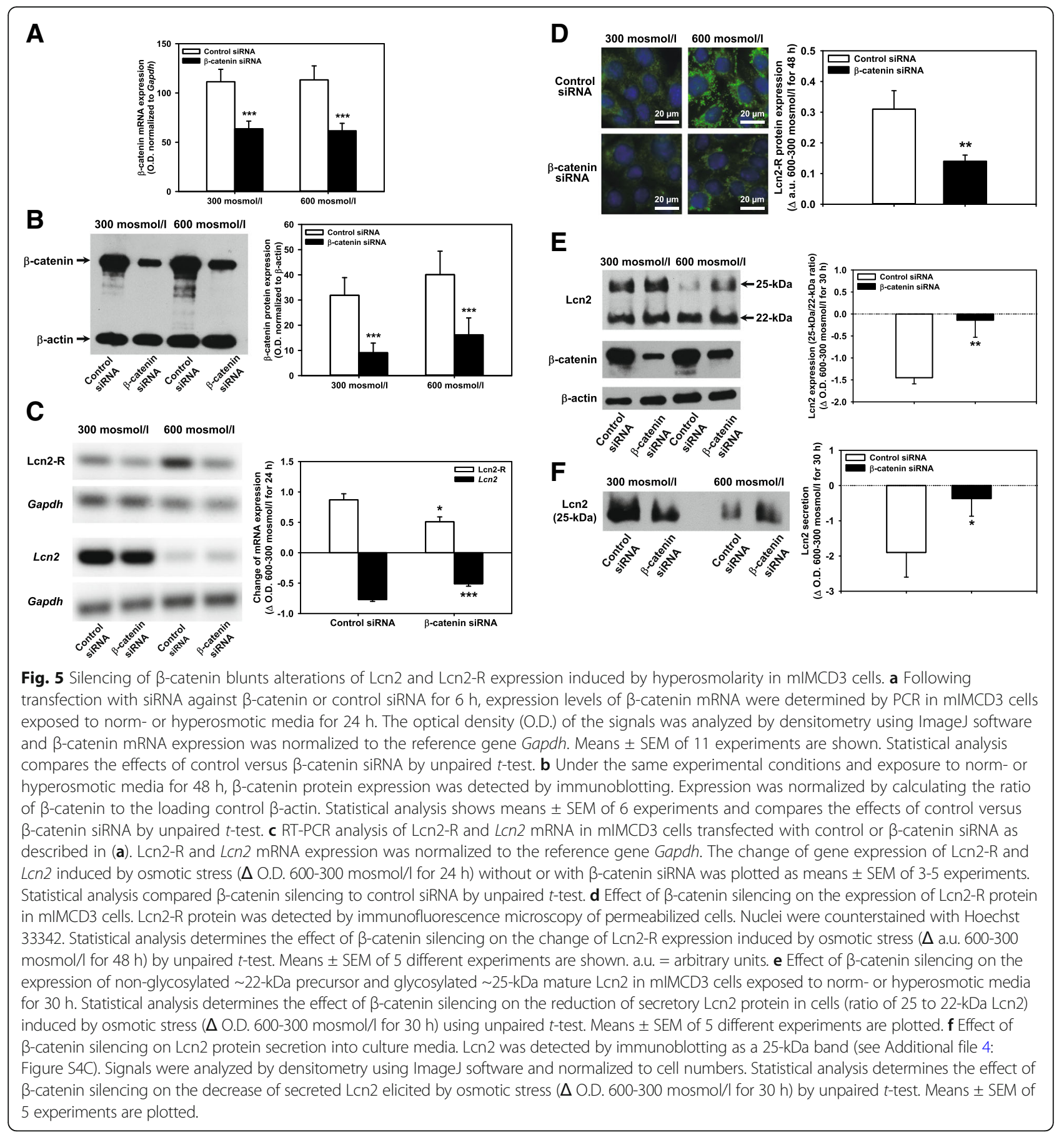

25-kDa mature Lcn2 [6, 11]. Only the latter was found to be secreted by mIMCD3 cells upon hyperosmolarity (Fig. 2c) or stimulation by the bacterial wall component LPS [14, 32] (Additional file 4: Figure S4C, lane 2). Increased osmolarity had a larger inhibitory effect on mature Lcn 2 formation which was almost completely reversed by $\beta$-catenin silencing (Fig. 5e, lanes 3 and 4). Little effect was seen on the precursor. Moreover, $\beta$-catenin siRNA significantly restored Lcn 2 secretion in hyperosmotic media (Fig. 5f, lanes 3 and 4). In conclusion, hyperosmolarity engages Wnt/ $\beta$-catenin signaling to inversely regulate Lcn2 and Lcn2-R (see also models in Fig. 7).

\section{LPS interferes with changes of Lcn2-R and Lcn2 expression/secretion induced by hyperosmolarity in mIMCD3 cells}

So far, we have evidenced that mIMCD3 cells increase Lcn2-R expression and suppress Lcn2 expression and 
secretion in a physiological high osmolarity context, which is regulated by $\mathrm{Wnt} / \mathrm{\beta}$-catenin signaling. The role of these mechanisms in a pathophysiological context was then explored, namely infection of the distal nephron by uropathogenic E. coli (UPEC), which represents the primary cause of UTI, including both cystitis and pyelonephritis [48]. To mimic bacterial infection by UPEC, we applied LPS to mIMCD3 cells in a hyperosmotic environment, which has been shown to elicit secretion of Lcn2 in kidney medulla [14]. Similarly as described in Fig. 2, exposure of mIMCD3 cells to hyperosmotic media decreased expression of Lcn2 mRNA (Fig. 6a and Additional file 4: Figure S4D, compare lanes 1 and 3) as well as expression of mature $(\sim 25 \mathrm{kDa})$ Lcn 2 protein and its secretion (Fig. 6b). Likewise, Lcn2-R $m R N A$ and protein expression were upregulated (Fig. $6 \mathrm{c}$ and Additional file 4: Figure S4E, compare lanes 1 and 3; Fig. 6d, compare upper and lower left panels) after $42 \mathrm{~h}$ or $72 \mathrm{~h}$ in hyperosmotic media, which recapitulates Fig. 1. Treatment with a saturating concentration of LPS $(5 \mu \mathrm{g} /$ ml) [32] (see Additional file 4: Figure S4B) during the last 18 h significantly reversed these effects, that is Lcn2 expression and secretion were partially restored (Fig. 6a and b, lane 4; Additional file 4: Figure S4D, lane 4) and Lcn2-R elevation was diminished (Fig. $6 \mathrm{c}$ and Additional file 4: Figure S4E, lane 4; Fig. 6d, compare lower left and right panels). Shorter LPS treatment periods than $18 \mathrm{~h}$ did not yield significant Lcn 2 secretion in normosmotic media (Additional file 4: Figure S4A). These data demonstrate that LPS mediated signaling counteracts hyperosmolarity induced regulation of Lcn2 and Lcn2-R expression in IMCD cells. Moreover, decreasing osmolarity to 300 mos$\mathrm{mol} / \mathrm{l}$ strongly enhanced LPS-induced Lcn2 expression and secretion (Fig. 6a and b, lanes 1 and 2) (see also models in Fig. $7 \mathrm{~b}$ and $\mathrm{c}$ ).

\section{LPS-induced Lcn2 secretion decreases viability of human Lcn2-R overexpressing CHO-K1 cells}

The role of the Lcn2- $R$ in induction of cell death during LPS-induced Lcn2 secretion was further investigated in $\mathrm{CHO}-\mathrm{K} 1$ cells with and without stable transfection of hLCN2-R isoform B and incubated in hyperosmotic media. Although comparable amounts of Lcn2 secretion was induced in both $\mathrm{CHO}-\mathrm{K} 1$ cell clones by incubation with LPS $(5 \mu \mathrm{g} / \mathrm{ml}$ for $48 \mathrm{~h})$ (Fig. 6e), only CHO-K1 cells overexpressing hLCN2-R isoform $B$ showed significant reduction in cell viability upon LPS treatment compared to pcDNA3.1 transfected cells (Fig. 6f).

Overall, these data suggest that LPS and/or reduced osmolarity increase the release of bacteriostatic $\mathrm{Fe}^{3+}$-free apo-Lcn2 into the urine and thus contribute to fighting bacterial UTIs, whereas downregulation of Lcn2-R may protect IMCD cells against damage and death induced by released apo-Lcn 2 (see also models in Figs. 7b and c).

\section{Discussion}

The study demonstrates that in a hyperosmotic environment, as encountered in vivo under physiological conditions in the kidney medulla, IMCD cells upregulate Lcn2-R and downregulate Lcn2, whereas the opposite is the case under normotonic conditions. Both Lcn 2 and Lcn2-R are downstream target genes of Wnt $/ \beta$-catenin signaling that may be activated as an adaptive measure to stress elicited by hyperosmolarity. The inverse regulation of Lcn2-R and Lcn 2 by Wnt/ $\beta$-catenin signaling may be relevant to prevent cell damage and death by Lcn 2 in a hyperosmotic environment and may be reversed during tubulo-interstitial diseases involving inflammation, e.g during UTI, where a normosmotic environment may more efficiently combat against bacterial infections (see Fig. 7c and below).

Increased $W n t / \beta$-catenin signaling was observed in mIMCD3 cells exposed to hyperosmotic media with increased expression of $W n t 5 a$ and $\beta$-catenin mRNA (Fig. 4a), suggesting an adaptive process. Induction of $W n t / \beta$-catenin signaling has not been described so far as an adaptive response to hyperosmotic stress in IMCD cells, but precedents exist from other cell types [23, 24]. Interestingly, increased $\mathrm{Wnt} / \beta$-catenin signaling paralleled a second phase of expression of cell cycle genes $M y c$ and $C c n d 1$ that were upregulated or restored after 72 h (Additional file 1: Figure S1B). Both $M y c$ and Ccnd1 are downstream target genes of the $\beta$-catenin/TCF transcription factor complex [49-51], and this induction could contribute to reactivation of proliferation in adapted cells.

Wnt/ק-catenin signaling seems to support and/or complement TonEBP/OREBP/NFAT5-mediated adaptive signaling. Whether the latter pathway is up- or downstream from Wnt/ $\beta$-catenin signaling, or represents a parallel pathway is currently unclear. The osmoprotective master regulator of hyperosmolarity TonEBP/OREBP/NFAT5 appears to represent an upstream activator of canonical Wnt signaling, as evidenced during cardiomyogenic differentiation [52]. In contrast, a study in intestinal cells suggested that TonEBP represses Wnt/ $\beta$-catenin signaling and thereby promotes enterocyte differentiation [53], but these may be cell-type specific effects unrelated to osmolarity induced cell proliferation and differentiation. Conversely, another study in HEK293 and mIMCD3 cells showed inhibitory phosphoryl-

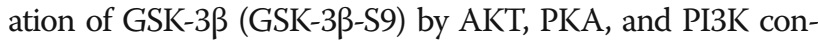
tributing to high $\mathrm{NaCl}$-induced activation of TonEBP/ OREBP/NFAT5, and suggests upstream regulation of TonEBP by Wnt/GSK-3 $\beta$ signaling [47]. Hence, it would be intriguing to assess the impact of osmotic stress-induced 

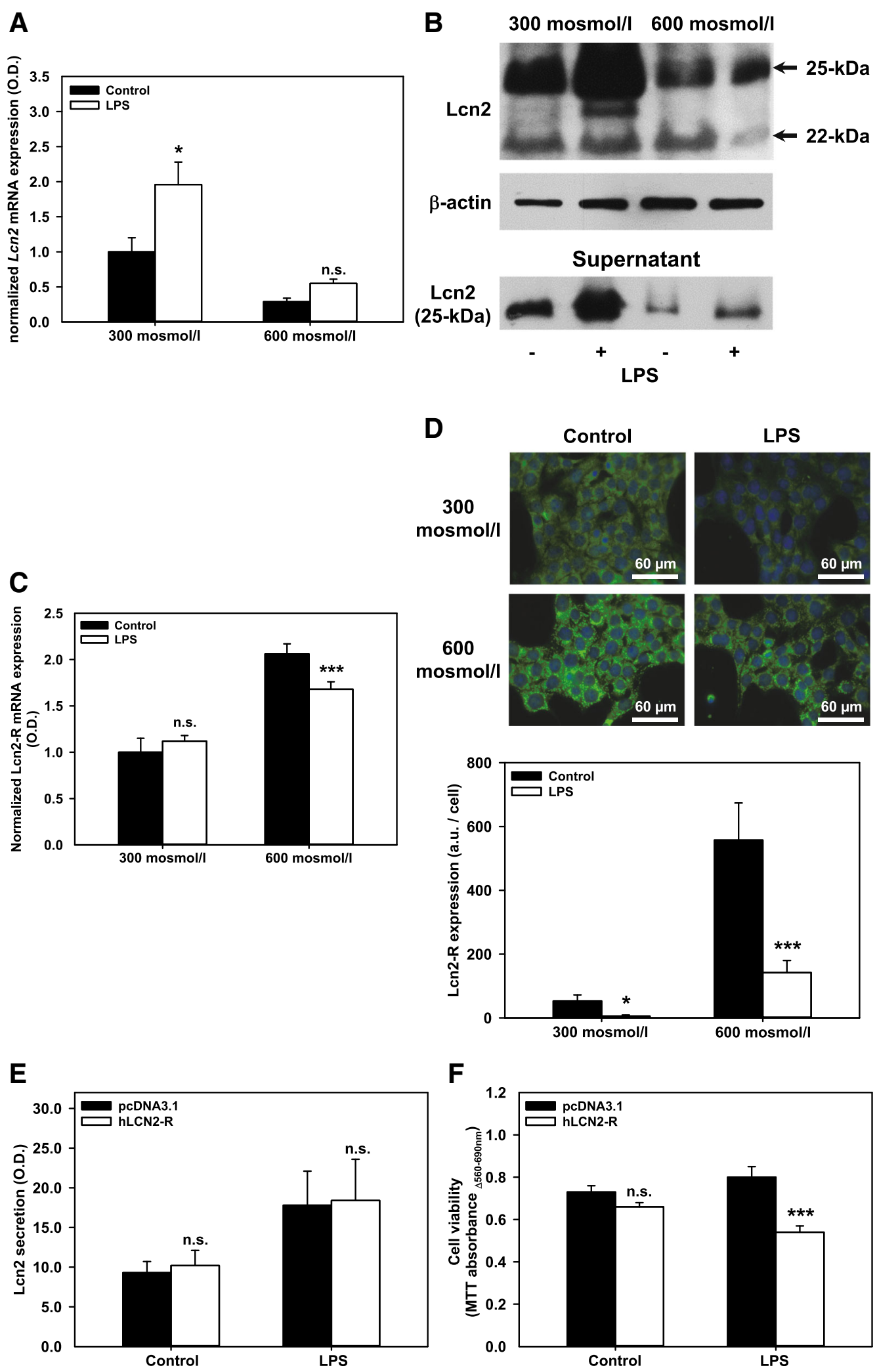

$\mathbf{F}$

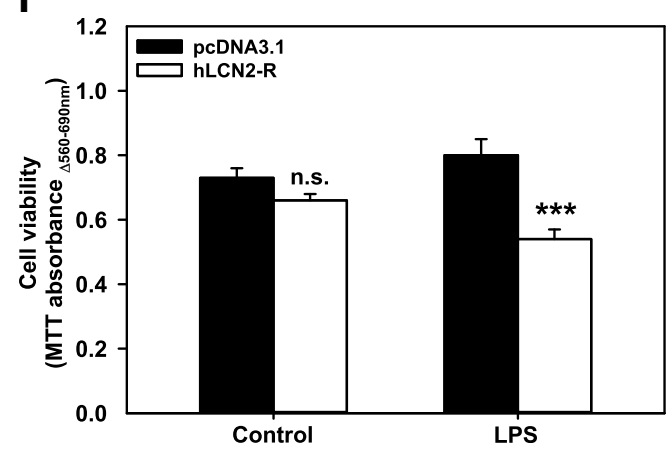

Fig. 6 (See legend on next page.) 
(See figure on previous page.)

Fig. 6 LPS reverts hyperosmolarity-induced changes of Len2-R/Len2 expression in mIMCD3 cells and decreases viability of CHO-K1 cells stably overexpressing hLCN2-R. mIMCD3 cells were exposed to norm- or hyperosmotic media for $24 \mathrm{~h}$ and \pm LPS for additional $18 \mathrm{~h}$. a RT-PCR analysis of Lcn2 mRNA, which was normalized to the reference gene Gapdh. Lcn2 gene expression, was plotted as means \pm SEM of 4 experiments. Statistical analysis determines the effect of LPS by unpaired $t$-test. n.s. = not significant. $\mathbf{b}$ Effect of LPS $(5 \mu \mathrm{g} / \mathrm{ml}$ for $18 \mathrm{~h})$ on the cellular expression of $22-\mathrm{kDa}$ precursor, 25-kDa mature Lcn2, and secretion of 25-kDa Lcn-2 in mIMCD3 cells. The experiment is representative of three similar ones. $\mathbf{c} L c n 2-R$ mRNA expression was determined by RT-PCR and normalized to the reference gene Gapdh. Means \pm SEM of 6 experiments are shown. Statistical analysis compares LPS to control by unpaired $t$-test. n.s. = not significant. $\mathbf{d}$ Effect of LPS on the expression of Len2-R in mIMCD3 cells exposed to norm- or hyperosmotic media for $24 \mathrm{~h}$ and \pm LPS $(5 \mu \mathrm{g} / \mathrm{ml}$ ) for additional $18 \mathrm{~h}$. Lcn2-R protein was detected by immunofluorescence microscopy of permeabilized cells. Nuclei were counterstained with Hoechst 33342. Lcn2-R protein expression at 300 and 600 mosmol/I \pm LPS was plotted as means \pm SEM of 4 experiments. Statistical analysis determines the effect of LPS by unpaired $t$-test. a.u. = arbitrary units. e Both, CHO-K1 cell clones stably transfected with pcDNA3.1 or human lipocalin-2 receptor isoform B (hLCN2-R), when grown in hyperosmotic media secrete similar amounts of Lcn2 upon treatment with LPS ( $5 \mu \mathrm{g} / \mathrm{ml}$ for $48 \mathrm{~h}$ ). Secretion of Lcn2 was determined by immunoblotting. The optical density (O.D.) of Lcn2 signals was quantified by densitometry using ImageJ software. Means \pm SEM of 4 experiments are plotted. $\mathbf{f}$ Cell viability of both clones stably transfected with pcDNA3.1 or hLCN2-R was measured by MTT assay. Data show means \pm SEM of 5-6 experiments with 6 replicates per experiment. Statistical analysis compares conditions $\pm \mathrm{hLCN2}$-R using unpaired $t$-test; $\mathrm{h}$.s. $=$ not significant.

TonEBP/OREBP/NFAT5 signaling on regulation of Lcn2 and Lcn2-R expression.

A previous in vivo study in mouse has demonstrated a link between osmolarity and Lcn2 expression. Aquaporin-1 null mice lack a functional countercurrent multiplier mechanism and fail to concentrate the inner medullary interstitium. In these mice, Lcn2 mRNA expression was increased in the inner medulla [54], which is in line with the data shown in Fig. 2. It is interesting that the $\sim 22-\mathrm{kDa}$ Lcn2 precursor was not affected by increased osmolarity (Fig. 5e, lanes 1 and 3) although gene expression was decreased (Figs. 2 and 5c, lanes 1 and 3). Still, the total amount of Lcn2 protein $(\sim 22-\mathrm{kDa}+\sim 25-\mathrm{kDa})$ as well as the ratio of mature to precursor Lcn2

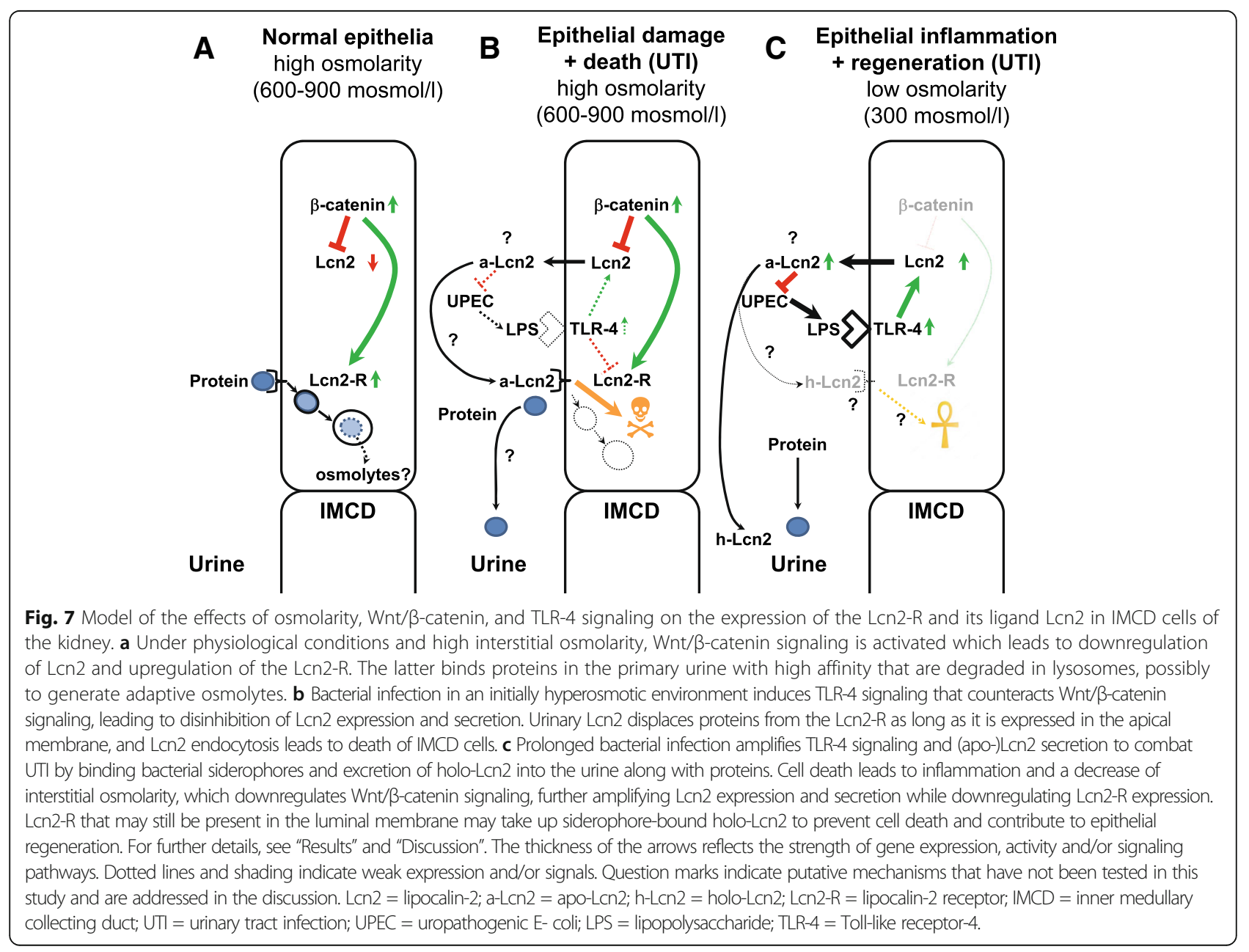


protein were also reduced (Figs. 2 and 5e), which suggests that high osmolarity influences both Lcn2 gene expression and trafficking/maturation.

No in vivo studies have been performed so far that would support our observations showing the upregulation of Lcn2-R by increased osmolarity (Fig. 1). Yet our previous data showing high Lcn2-R expression in normal kidney medulla in rodents [16] as well as recent data obtained by deep sequencing in microdissected rat IMCD where in Lcn2-R had the highest expression from all nephron segments and Lcn2 levels were negligible [55] support our observations. Moreover, progressive kidney tubulo-interstitial damage (e.g. due to recurring bacterial infections, renal ischemia, or proteinuric nephropathies), which impairs the renal capacity to concentrate urine [1, 56, 57], results in reduction of Lcn2-R expression [17], concomitantly with an increase of Lcn2 expression ([14] and this study).

The inverse regulation of Lcn 2 and Lcn2-R induced by osmolarity via $\mathrm{Wnt} / \beta$-catenin signaling is not unique to renal medullary cells and has been reported in other cell types. Previous studies in cancer cells have already demonstrated an inverse relationship between Lcn2 and Lcn2-R expression. In murine myeloblast-like cells, the oncogene BCR-ABL activated the JAK/STAT pathway, which increased Lcn2, and repressed Lcn2-R expression in a Ras and Runx1-dependent manner [8,9].

Although other signaling pathways likely regulate Lcn2 and Lcn2-R expression, the contribution of $\beta$-catenin was strong, accounting for $\sim 50 \%$ of Lcn $2-\mathrm{R}$ expression (Fig. 5c and d) and more than $80 \%$ of Lcn 2 expression and secretion (Fig. 5e and f) despite incomplete $\beta$-catenin silencing (Fig. 5 and Additional file 3: Figure S3). These results support findings from Ziegler et al. showing that the Wnt/ $\beta$-catenin pathway inhibits the $L c n 2$ promoter $[25,26]$. Although the study by Ziegler et al. only showed Wnt/B-catenin-dependent differential splicing of Lcn2-R transcripts [25], in silico analysis supports the hypothesis that Lcn2-R is a downstream target of $\mathrm{Wnt} / \beta$-catenin signaling. Putative transcription factor binding sites in the DNA sequence flanking murine Lcn2-R (Slc22a17) were analyzed $[58,59]$ wherein a putative TCF1 binding site was found 111 bases upstream of the Slc22a17 gene indicating a possible binding domain in the promoter region and supporting the hypothesis that Lcn2-R is a direct target gene of $W n t / \beta$-catenin signaling.

The significance of upregulation of $L \mathrm{cn} 2-\mathrm{R}$ in a physiological hyperosmotic environment is difficult to test as long as kidney-specific knockout animals are not available. We have previously demonstrated that Lcn2-R is involved in high-affinity protein endocytosis in the distal nephron [16] and suggested that the Lcn2-R could contribute to clearance of filtered proteins by the nephron under physiological conditions. Support for the hypothesis that Lcn2-R may endocytose luminal proteins in the distal nephron has been recently provided for its natural ligand Lcn2 [60]. Endocytosed proteins are trafficked to lysosomes [16] where they are degraded. It is therefore not unreasonable to speculate that the Lcn2-R may contribute to adaptation to osmotic stress by providing amino acids as precursors/osmolytes to IMCD cells to maintain isoosmolarity with the interstitium. But this remains to be proven. Prevention of Lcn2 expression and secretion, on the other hand, would also avert death-promoting effects of (apo-)Lcn2 in cells that are already osmotically stressed (Figs. 3 and 6).

The ligand of Lcn2-R, Lcn2 [19, 31], is secreted by the renal $C D[12,14]$ where it contributes to limitation of tubular stress and injury caused by a number of insults, e.g. by exerting bacteriostatic effects [61, 62]. Parallel expression/secretion of Lcn2-R and Lcn2 under conditions of renal medullary hyperosmolarity, which may be encountered during early stages of bacterial infection, would be deleterious for two reasons: 1) autocrine or paracrine endocytosis of secreted (apo-)Lcn2 would promote cell damage [8] (see also Figs. 3 and 6) rather than limit the insult; and 2) endocytosis of Lcn2 via Lcn2-R would reduce the availability of Lcn 2 in the lumen and thereby reduce the siderophore- $\mathrm{Fe}^{3+}$ scavenging and bacteriostatic effect of apo-Lcn2. Downregulation of Lcn2-R as well as upregulation and increased secretion of Lcn2 induced by an isosmotic interstitium and/or LPS, which may be encountered during inflammationassociated hyperperfusion and/or late reparative stages of bacterial infection [56, 57], could offset these detrimental consequences (see Fig. 7c). LPS-induced activation of the TLR-4 pathway [14] opposes TonEBP/OREBP/ NFAT5 signaling [63] and could possibly also counteract Wnt $/ \beta$-catenin signaling induced by hyperosmolarity.

Of course, the consequences and outcome would be entirely different in case of the presence of siderophore $\mathrm{Fe}^{3+}$-loaded holo-Lcn2 in the tubular lumen that is known to promote repair, survival and proliferation of normal [64] and cancerous cells [65]. In this case, co-expression/secretion of Lcn2-R and holo-Lcn 2 would be desirable for epithelial proliferation and regeneration (see Fig. 7c). Sporadic evidence for this hypothesis has been obtained from cancer studies (reviewed in [10]), but systemic studies investigating the role of apo- versus holo-Len2 in renal epithelial regeneration following various insults would be desirable. On the other hand, it is interesting to note that we have previously obtained evidence that siderophore $\mathrm{Fe}^{3+}$-loaded human holo-LCN2 binds with lower affinity to the $\mathrm{N}$-terminus of human LCN2-R than apo-LCN2 [31]. Though speculative, this observation could signify that luminal holo-LCN2 may be more dedicated to 
excretion into the urine as an effective bacteriostatic measure to dispose of luminal iron rather than to auto- or paracrine uptake (see Fig. 7b and c) .

\section{Conclusions}

In summary, Lcn2-R up- and Lcn2 downregulation via Wnt $/ \beta$-catenin may promote adaptive survival of IMCD cells in response to hyperosmolarity whereas Lcn2 up- and Lcn2-R downregulation via LPS/TLR-4 and/or normosmolarity may protect IMCD cells against bacterial infections and prevent autocrine death induction by secreted (apo-)Lcn2.

\section{Additional files}

Additional file 1: Figure S1. Hyperosmolarity inhibits proliferation and induces adaptive responses in mIMCD3 cells. (A) Proliferation of mIMCD3 cells cultured in media without (normosmolarity) or with $100 \mathrm{mmol} / \mathrm{l}$ urea and $\mathrm{NaCl}$ (hyperosmolarity) for $72 \mathrm{~h}$. Measurements of MTT absorbance/optical density (O.D.) reflecting cell proliferation were performed at indicated time points. Means \pm SEM of 5 experiments are shown. Statistical analysis compares the two osmotic conditions at each time point by unpaired t-test. (B) Expression levels of proliferation genes c-Myc (Myc) and cyclin D1 (Ccnd1) by qPCR in mIMCD3 cells exposed to norm- or hyperosmotic media for $72 \mathrm{~h}$. The data obtained were normalized to the expression of the reference genes glyceraldehyde-3-phosphate dehydrogenase (Gapdh), $\beta$-actin (Actb), and $\beta 2$-microglobulin (B2m). Means \pm SEM of 3-5 experiments are shown. Statistical analysis compares the two osmotic conditions by unpaired $t$-test. (C) Surface expression of $\mathrm{Na}^{+}, \mathrm{K}^{+}$-ATPase in mIMCD3 cells exposed to norm- or hyperosmotic media for $72 \mathrm{~h}$. Immunofluorescence microscopy was performed in non-permeabilized cells. Nuclei were counterstained with Hoechst 33342. Images are representative of three individual experiments. (D) Expression of a1-subunit of $\mathrm{Na}^{+}, \mathrm{K}^{+}$-ATPase in homogenate $(\mathrm{Ho})$ and plasma membranes (PM) of mIMCD3 cells grown for $72 \mathrm{~h}$ in norm- or hyperosmotic media. Expression was determined by immunoblotting. $\beta$-actin was used as a loading control. Image represents three independent experiments. (PDF 361 kb)

Additional file 2: Figure S2. Verification of hLCN2-R isoform B expression in stable CHO-K1 cell transfectants. (A) Reverse transcription PCR of hLCN2-R-isoform B CHO-K1 clone D6.D10. RNA isolation and cDNA synthesis were carried out as described [31]. Primers and cycling conditions are listed in Table 1. (B) Immunoblot of pcDNA3.1 and hLCN2-R isoform B CHO-K1 cells. Cells were grown to confluency, washed once with PBS, harvested by scraping, and suspended in buffer containing $250 \mathrm{mM}$ sucrose, $5 \mathrm{mM}$ Tris, $\mathrm{pH} 7.5$, and protease inhibitors. Homogenization by sonication and immunoblotting were carried out as described in the Methods. (PDF $96 \mathrm{~kb}$ )

Additional file 3: Figure S3. $\beta$-catenin siRNA reduces $\beta$-catenin mRNA expression in mIMCD3 cells exposed to norm- or hyperosmotic media. (A) mIMCD3 cells exposed to norm- or hyperosmotic media for $24 \mathrm{~h}$ were transfected with siRNA against $\beta$-catenin or control siRNA for $6 \mathrm{~h}$, and expression levels of $\beta$-catenin mRNA were determined by PCR in norm- or hyperosmotic media after additional $24 \mathrm{~h}$. (B) Silencing was stable between 16 and $48 \mathrm{~h}$ after transfection. Gapdh was used as reference gene. The experiments are representative of at least three similar ones. (PDF $199 \mathrm{~kb}$ )

Additional file 4: Figure S4. LPS induces Lcn2 expression and secretion and counteracts the effects of hyperosmolarity on Lcn2 and Lcn2-R expression in mIMCD3 cells. (A) Cells were cultured for $24 \mathrm{~h}$ in normosmotic medium with FBS, as described in the Methods and the medium was replaced by normosmotic medium without FBS \pm LPS $(5 \mu \mathrm{g} / \mathrm{ml})$ for various time points. Medium was concentrated using Vivaspin 500 Centrifugal Concentrators (10 kDa MW cut-off) prior to immunoblotting. (B) Cells were cultured in normosmotic medium, as described in $(\mathbf{A})$, prior to treatment with different concentrations of LPS for $18 \mathrm{~h}$ in the same medium without FBS. Medium was collected and Lcn2 secretion determined by immunoblotting, as described above. (C) mIMCD3 cells were cultured as described above and treated \pm LPS $(5 \mu \mathrm{g} / \mathrm{ml})$ for $18 \mathrm{~h}$ in normosmotic medium without FBS prior to medium collection and measurement of Lcn2 secretion by immunoblotting. Cells were washed, scraped and homogenized by sonication in isosmotic sucrose buffer supplemented with protease inhibitors for immunoblotting. (D, E) mIMCD3 cells were exposed to norm- or hyperosmotic media for $24 \mathrm{~h}$ and treated \pm LPS $(5 \mathrm{m \mu g} / \mathrm{ml})$ for additional $18 \mathrm{~h}$ in the same media without FBS prior to RNA isolation. RT-PCR shows mRNA expression for Lcn2 (D), Lcn2-R (E) and the reference gene Gapdh. The experiments are representative of at least three similar ones. (PDF $96 \mathrm{~kb}$ )

\section{Acknowledgments}

Not applicable.

\section{Funding}

This work was supported by the Deutsche Forschungsgemeinschaft (DFG TH345/11-1), a BMBF grant between Germany and Mexico (BMBF 01DN16039), and the Centre for Biomedical Training and Research (ZBAF) of the University of Witten/Herdecke.

\section{Availability of data and materials}

The datasets used and/or analyzed during the current study are available from the corresponding author on reasonable request.

\section{Authors' contributions}

$\mathrm{RB}, \mathrm{BS}, \mathrm{SP} B \mathrm{BE} N \mathrm{NW}$ and $\mathrm{CL}$ performed experiments, analyzed data and wrote the paper. WKL designed experiments, interpreted data and wrote the paper. FT initiated the study, designed experiments, analyzed and interpreted data and wrote the paper. All authors read and approved the final manuscript.

\section{Ethics approval and consent to participate}

Not applicable.

\section{Consent for publication}

Not applicable.

\section{Competing interests}

The authors declare that they have no competing interests.

\section{Publisher's Note}

Springer Nature remains neutral with regard to jurisdictional claims in published maps and institutional affiliations.

\section{Author details}

${ }^{1}$ Department of Physiology, Pathophysiology \& Toxicology and ZBAF (Centre for Biomedical Education and Research), Faculty of Health, School of Medicine, Witten/Herdecke University, Stockumer Str 12 (Thyssenhaus), D-58453 Witten, Germany. '2Department of Medicine, Hematology and Oncology, Martin Luther University Halle-Wittenberg, 06120 Halle (Saale), Germany.

Received: 2 September 2018 Accepted: 18 October 2018

Published online: 07 November 2018

\section{References}

1. Knepper MA, Hoffert JD, Packer RK, Urine Concentration FRA. Dilution. In: Brenner BM, editor. Brenner \& Rector's The Kidney. 1. 8 ed. Philadelphia: Saunders; 2008. p. 308-29.

2. Ullrich KJ, Drenckhahn FO, Jarausch KH. Studies on the problem of urine concentration and dilution; osmotic behavior of renal cells and accompanying electrolyte accumulation in renal tissue in various diuretic conditions. Pflugers Arch Gesamte Physiol Menschen Tiere. 1955;261:62-77.

3. Jarausch $\mathrm{KH}$, Ullrich KJ. Studies on the problem of urine concentration and dilution; distribution of electrolytes (sodium, potassium, calcium, magnesium, anorganic phosphate), urea amino acids and exogenous creatinine in the cortex and medulla of dog kidney in various diuretic conditions. Pflugers Arch Gesamte Physiol Menschen Tiere. 1956;262:537-50. 
4. Burg MB, Ferraris JD, Dmitrieva NI. Cellular response to hyperosmotic stresses. Physiol Rev. 2007;87:1441-74.

5. Schulze Blasum B, Schroter R, Neugebauer U, Hofschroer V, Pavenstadt $H$, Ciarimboli $\mathrm{G}$, et al. The kidney-specific expression of genes can be modulated by the extracellular osmolality. FASEB J. 2016;30:3588-97.

6. Kjeldsen $L$, Johnsen AH, Sengelov H, Borregaard N. Isolation and primary structure of NGAL, a novel protein associated with human neutrophil gelatinase. J Biol Chem. 1993;268:10425-32.

7. Abergel RJ, Clifton MC, Pizarro JC, Warner JA, Shuh DK, Strong RK, et al. The siderocalin/enterobactin interaction: a link between mammalian immunity and bacterial iron transport. J Am Chem Soc. 2008;130:11524-34.

8. Devireddy LR, Gazin C, Zhu X, Green MR. A cell-surface receptor for lipocalin 24p3 selectively mediates apoptosis and iron uptake. Cell. 2005;123:1293-305.

9. Sheng Z, Wang SZ, Green MR. Transcription and signalling pathways involved in BCR-ABL-mediated misregulation of $24 \mathrm{p} 3$ and $24 \mathrm{p} 3 \mathrm{R}$. EMBO J. 2009:28:866-76.

10. Jung M, Weigert A, Mertens C, Rehwald C, Brune B. Iron Handling in TumorAssociated Macrophages-Is There a New Role for Lipocalin-2? Front Immunol. 2017;8:1171.

11. Chu ST, Huang HL, Chen JM, Chen YH. Demonstration of a glycoprotein derived from the $24 \mathrm{p} 3$ gene in mouse uterine luminal fluid. Biochem J. 1996;316:545-50.

12. Paragas N, Qiu A, Zhang Q, Samstein B, Deng SX, Schmidt-Ott KM, et al. The Ngal reporter mouse detects the response of the kidney to injury in real time. Nat Med. 2011;17:216-22

13. Correnti C, Strong RK. Mammalian siderophores, siderophore-binding lipocalins, and the labile iron pool. J Biol Chem. 2012;287:13524-31.

14. Paragas N, Kulkarni R, Werth M, Schmidt-Ott KM, Forster C, Deng R, et al. alpha-Intercalated cells defend the urinary system from bacterial infection. J Clin Invest. 2014;124:2963-76.

15. Cowland JB, Sorensen OE, Sehested M, Borregaard N. Neutrophil gelatinaseassociated lipocalin is up-regulated in human epithelial cells by IL-1 beta, but not by TNF-alpha. J Immunol. 2003;171:6630-9.

16. Langelueddecke C, Roussa E, Fenton RA, Wolff NA, Lee WK, Thévenod F. Lipocalin-2 (24p3/neutrophil gelatinase-associated lipocalin (NGAL)) receptor is expressed in distal nephron and mediates protein endocytosis. J Biol Chem. 2012:287:159-69.

17. Dizin E, Hasler U, Nlandu-Khodo S, Fila M, Roth I, Ernandez T, et al. Albuminuria induces a proinflammatory and profibrotic response in cortical collecting ducts via the $24 \mathrm{p} 3$ receptor. Am J Physiol Renal Physiol. 2013;305:F1053-F63.

18. Thévenod F, Wolff NA. Iron transport in the kidney: implications for physiology and cadmium nephrotoxicity. Metallomics. 2016;8:17-42.

19. Devireddy LR, Teodoro JG, Richard FA, Green MR. Induction of apoptosis by a secreted lipocalin that is transcriptionally regulated by IL-3 deprivation. Science. 2001:293:829-34

20. Hvidberg V, Jacobsen C, Strong RK, Cowland JB, Moestrup SK, Borregaard N. The endocytic receptor megalin binds the iron transporting neutrophilgelatinase-associated lipocalin with high affinity and mediates its cellular uptake. FEBS Lett. 2005:579:773-7.

21. Christensen El, Birn H. Megalin and cubilin: multifunctional endocytic receptors. Nat Rev Mol Cell Biol. 2002;3:256-66.

22. Nusse R, Clevers H. Wnt/beta-Catenin Signaling, Disease, and Emerging Therapeutic Modalities. Cell. 2017:169:985-99.

23. Madonna R, Geng YJ, Shelat H, Ferdinandy P, De Caterina R. High glucoseinduced hyperosmolarity impacts proliferation, cytoskeleton remodeling and migration of human induced pluripotent stem cells via aquaporin-1. Biochim Biophys Acta. 2014;1842:2266-75.

24. Lin CL, Wang JY, Huang YT, Kuo YH, Surendran K, Wang FS. Wnt/betacatenin signaling modulates survival of high glucose-stressed mesangial cells. J Am Soc Nephrol. 2006;17:2812-20.

25. Ziegler S, Rohrs S, Tickenbrock L, Langerak A, Chu ST, Feldmann I, et al. Lipocalin $24 p 3$ is regulated by the Wnt pathway independent of regulation by iron. Cancer Genet Cytogenet. 2007;174:16-23.

26. Ziegler S, Rohrs S, Tickenbrock L, Moroy T, Klein-Hitpass L, Vetter IR, et al. Novel target genes of the Wnt pathway and statistical insights into Wnt target promoter regulation. The FEBS J. 2005;272:1600-15.

27. Rauchman MI, Nigam SK, Delpire E, Gullans SR. An osmotically tolerant inner medullary collecting duct cell line from an SV40 transgenic mouse. Am J Physiol. 1993;265:F416-24.
28. Riethmuller C, Oberleithner H, Wilhelmi M, Franz J, Schlatter E, Klokkers J, et al. Translocation of aquaporin-containing vesicles to the plasma membrane is facilitated by actomyosin relaxation. Biophys J. 2008;94:671-8.

29. Ohtaka A, Muto S, Nemoto J, Kawakami K, Nagano K, Asano Y. Hyperosmolality stimulates Na-K-ATPase gene expression in inner medullary collecting duct cells. Am J Physiol. 1996;270:F728-38.

30. Capasso JM, Rivard CJ, Berl T. Long-term adaptation of renal cells to hypertonicity: role of MAP kinases and Na-K-ATPase. Am J Physiol Renal Physiol. 2001;280:F768-76.

31. Cabedo Martinez Al, Weinhaupl K, Lee WK, Wolff NA, Storch B, Zerko S, et al. Biochemical and Structural Characterization of the Interaction between the Siderocalin NGAL/LCN2 (Neutrophil Gelatinase-associated Lipocalin/ Lipocalin 2) and the N-terminal Domain of Its Endocytic Receptor SLC22A17. J Biol Chem. 2016;291:2917-30

32. Kuper C, Beck FX, Neuhofer W. Toll-like receptor 4 activates NF-kappaB and MAP kinase pathways to regulate expression of proinflammatory COX-2 in renal medullary collecting duct cells. Am J Physiol Renal Physiol. 2012;302:F38-46.

33. Lee WK, Bork U, Gholamrezaei F, Thévenod F. Cd2+-induced cytochrome c release in apoptotic proximal tubule cells: role of mitochondrial permeability transition pore and Ca2+ uniporter. Am J Physiol Renal Physiol. 2005;288:F27-39

34. Chakraborty PK, Lee WK, Molitor M, Wolff NA, Thévenod F. Cadmium induces Wht signaling to upregulate proliferation and survival genes in sub-confluent kidney proximal tubule cells. Mol Cancer. 2010;9:102.

35. Nair AR, Lee WK, Smeets K, Swennen Q, Sanchez A, Thévenod F, et al. Glutathione and mitochondria determine acute defense responses and adaptive processes in cadmium-induced oxidative stress and toxicity of the kidney. Arch Toxicol. 2015;89:2273-89.

36. Bustin SA, Benes V, Garson JA, Hellemans J, Huggett J, Kubista M, et al. The MIQE guidelines: minimum information for publication of quantitative realtime PCR experiments. Clin Chem. 2009:55:611-22.

37. Bradford MM. A rapid and sensitive method for the quantitation of microgram quantities of protein utilizing the principle of protein-dye binding. Anal Biochem. 1976;72:248-54.

38. Lee WK, Chakraborty PK, Roussa E, Wolff NA, Thévenod F. ERK1/2dependent bestrophin-3 expression prevents ER-stress-induced cell death in renal epithelial cells by reducing CHOP. Biochim Biophys Acta. 2012;1823:1864-76

39. Lowry O, Rosebrough N, Farr A, Randall RJ. Protein measurements with the Folin phenol reagent. J Biol Chem. 1951;194:265-75.

40. Schneider CA, Rasband WS, Eliceiri KW. NIH Image to ImageJ: 25 years of image analysis. Nat Methods. 2012;9:671-5.

41. Wolff NA, Abouhamed M, Verroust PJ, Thévenod F. Megalin-dependent internalization of cadmium-metallothionein and cytotoxicity in cultured renal proximal tubule cells. J Pharmacol Exp Ther. 2006;318:782-91.

42. Klokkers J, Langehanenberg P, Kemper B, Kosmeier S, von Bally G, Riethmuller $C$, et al. Atrial natriuretic peptide and nitric oxide signaling antagonizes vasopressin-mediated water permeability in inner medullan collecting duct cells. Am J Physiol Renal Physiol. 2009;297:F693-703.

43. Mishra J, Dent C, Tarabishi R, Mitsnefes MM, Ma Q, Kelly C, et al. Neutrophil gelatinase-associated lipocalin (NGAL) as a biomarker for acute renal injury after cardiac surgery. Lancet. 2005:365:1231-8.

44. Richardson DR. 24p3 and its receptor: dawn of a new iron age? Cell. 2005; 123:1175-7.

45. Chakraborty PK, Scharner B, Jurasovic J, Messner B, Bernhard D, Thévenod F. Chronic cadmium exposure induces transcriptional activation of the Wnt pathway and upregulation of epithelial-to-mesenchymal transition markers in mouse kidney. Toxicol Lett. 2010;198:69-76.

46. Clevers H, Nusse R. Wnt/beta-catenin signaling and disease. Cell. 2012;149; 1192-205.

47. Zhou X, Wang H, Burg MB, Ferraris JD. Inhibitory phosphorylation of GSK3beta by AKT, PKA, and PI3K contributes to high NaCl-induced activation of the transcription factor NFAT5 (TonEBP/OREBP). Am J Physiol Renal Physiol. 2013;304:F908-17

48. Wiles TJ, Kulesus RR, Mulvey MA. Origins and virulence mechanisms of uropathogenic Escherichia coli. Exp Mol Pathol. 2008;85:11-9.

49. He TC, Sparks AB, Rago C, Hermeking H, Zawel L, da Costa LT, et al. Identification of C-MYC as a target of the APC pathway. Science. 1998;281:1509-12.

50. Tetsu O, McCormick F. Beta-catenin regulates expression of cyclin D1 in colon carcinoma cells. Nature. 1999;398:422-6. 
51. Shtutman M, Zhurinsky J, Simcha I, Albanese C, D'Amico M, Pestell R, et al. The cyclin D1 gene is a target of the beta-catenin/LEF-1 pathway. Proc Natl Acad Sci U S A. 1999;96:5522-7.

52. Adachi A, Takahashi T, Ogata T, Imoto-Tsubakimoto H, Nakanishi N, Ueyama T, et al. NFAT5 regulates the canonical Wnt pathway and is required for cardiomyogenic differentiation. Biochem Biophys Res Commun. 2012;426:317-23.

53. Wang Q, Zhou Y, Rychahou P, Liu C, Weiss HL, Evers BM. NFAT5 represses canonical Wnt signaling via inhibition of beta-catenin acetylation and participates in regulating intestinal cell differentiation. Cell Death Dis. 2013;4:e671.

54. McReynolds MR, Taylor-Garcia KM, Greer KA, Hoying JB, Brooks HL. Renal medullary gene expression in aquaporin-1 null mice. Am J Physiol Renal Physiol. 2005;288:F315-21.

55. Lee JW, Chou CL, Knepper MA. Deep Sequencing in Microdissected Renal Tubules Identifies Nephron Segment-Specific Transcriptomes. J Am Soc Nephrol. 2015;26:2669-77.

56. Basile DP, Donohoe D, Roethe K, Osborn JL. Renal ischemic injury results in permanent damage to peritubular capillaries and influences long-term function. Am J Physiol Renal Physiol. 2001;281:F887-99.

57. Grinevich V, Knepper MA, Verbalis J, Reyes I, Aguilera G. Acute endotoxemia in rats induces down-regulation of $\mathrm{V} 2$ vasopressin receptors and aquaporin2 content in the kidney medulla. Kidney Int. 2004;65:54-62.

58. Messeguer X, Escudero R, Farre D, Nunez O, Martinez J, Alba MM. PROMO: detection of known transcription regulatory elements using species-tailored searches. Bioinformatics. 2002;18:333-4.

59. Farre D, Roset R, Huerta M, Adsuara JE, Rosello L, Alba MM, et al. Identification of patterns in biological sequences at the ALGGEN server: PROMO and MALGEN. Nucleic Acids Res. 2003;31:3651-3.

60. Barasch J, Hollmen M, Deng R, Hod EA, Rupert PB, Abergel RJ, et al. Disposal of iron by a mutant form of lipocalin 2. Nat Commun. 2016;7:12973.

61. Flo TH, Smith KD, Sato S, Rodriguez DJ, Holmes MA, Strong RK, et al. Lipocalin 2 mediates an innate immune response to bacterial infection by sequestrating iron. Nature. 2004;432:917-21.

62. Berger T, Togawa A, Duncan GS, Elia AJ, You-Ten A, Wakeham A, et al. Lipocalin 2-deficient mice exhibit increased sensitivity to Escherichia coli infection but not to ischemia-reperfusion injury. Proc Natl Acad Sci U S A. 2006:103:1834-9.

63. Hasler U, Leroy V, Jeon US, Bouley R, Dimitrov M, Kim JA, et al. NF-kappaB modulates aquaporin-2 transcription in renal collecting duct principal cells. J Biol Chem. 2008;283:28095-105.

64. Schmidt-Ott KM, Mori K, Li JY, Kalandadze A, Cohen DJ, Devarajan P, et al. Dual action of neutrophil gelatinase-associated lipocalin. J Am Soc Nephrol. 2007;18:407-13.

65. Torti SV, Torti FM. Iron and cancer: more ore to be mined. Nat Rev Cancer. 2013;13:342-55

Ready to submit your research? Choose BMC and benefit from:

- fast, convenient online submission

- thorough peer review by experienced researchers in your field

- rapid publication on acceptance

- support for research data, including large and complex data types

- gold Open Access which fosters wider collaboration and increased citations

- maximum visibility for your research: over $100 \mathrm{M}$ website views per year

At $\mathrm{BMC}$, research is always in progress.

Learn more biomedcentral.com/submissions 